
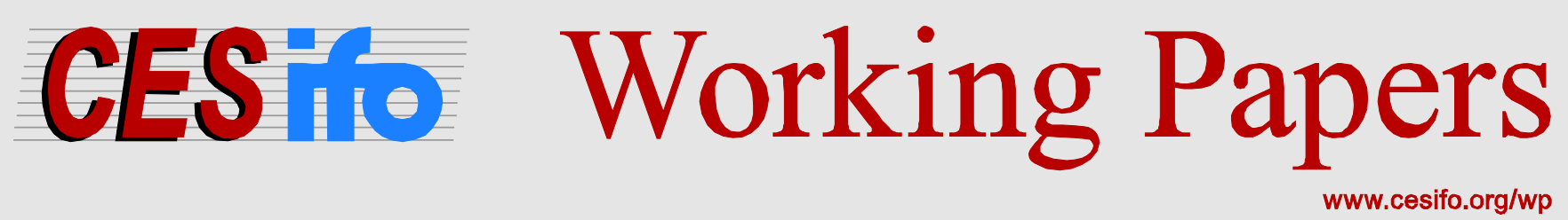

\title{
Manufacturers Mergers and Product Variety in Vertically Related Markets
}

\author{
Chrysovalantou Milliou \\ Joel Sandonis
}

CESIFO WORKING PAPER NO. 4932

CATEGORY 11: INDUSTRIAL ORGANISATION

August 2014

An electronic version of the paper may be downloaded

- from the SSRN website:

- from the RePEc website:

- from the CESifo website:

wWw.SSRN.com

Www.RePEc.org

www.CESifo-group.org/wp

\section{CESifo}




\title{
Manufacturers Mergers and Product Variety in Vertically Related Markets
}

\begin{abstract}
We study final product manufacturers' incentives to introduce new products into the market and how they are affected by a merger among them. We show that when manufacturers distribute their products through multi-product retailers, a manufacturers merger, although it leads to an increase in the wholesale prices, it can enhance product variety. The merger generated product variety efficiencies though arise only when vertical relations are present: when manufacturers sell directly their products to consumers, a merger never results into more product variety. Still, both in the presence and in the absence of vertical relations, a manufacturers merger is harmful to consumers and welfare.
\end{abstract}

JEL-Code: L110, L130, L410, L420.

Keywords: horizontal mergers, product variety, vertical relations.

Chrysovalantou Milliou

Department of International and European

Economic Studies

Athens University of Economics

and Business

Greece - Athens 10434

cmilliou@aueb.gr
Joel Sandonis

Department of Economics

University of Alicante

Spain - 03080 Alicante

sandonis@ua.es

July 2014

The first author gratefully acknowledges financial support from the Research Support Program - Action 1 of the Athens University of Economics and Business. The second author gratefully acknowledges financial support from Ministerio de Ciencia e Innovación and FEDER funds under SEJ 2007-62656, Generalitat Valenciana under grant PROMETEO/2013/037 and from Ministerio de Economía y Competitividad under project ECO2012-34928. 


\section{Introduction}

A common business strategy of final product manufacturers is product proliferation, that is, the offering of different variations of the same final product by a single manufacturer. Kellogg's, for instance, offers more than 20 different varieties of cereals, Ben \& Jerry's sells 39 varieties of ice-cream, and Colgate and Crest each delivers more than 35 types of toothpaste. ${ }^{1}$

Another common business strategy of final product manufacturers is the mergers among them. Manufacturer mergers take place in various industry sectors. For instance, in the automobile industry, the German carmaker, Volkswagen is on track to finalize the full takeover of the sports car manufacturer, Porsche. ${ }^{2}$ Moreover, in the mobile phone manufacturing market, Sony and Ericsson have merged in the past with each other, and so have done Colgate-Palmolive and Sanex in the market of personal care goods, Oracle and PeopleSoft in the software programs market, and Panasonic and Sanyo in the electronics manufacturing market. $^{3}$

One of the recent concerns of the U.S. antitrust authorities regarding manufacturer mergers is whether and how they alter the merged firms' decisions regarding their product lines, and in turn, how they affect product variety in the market. This concern has been explicitly expressed in the most recent U.S. Horizontal Merger Guidelines (2010) which state that the authorities should focus not only on the impact of horizontal mergers on cost-related efficiencies, but also on their potential impact on product variety. Furthermore, in the assessment of a number of merger cases, the U.S. antitrust authorities, have incorporated the merger's impact on product variety. For example, in 2003, the Federal Trade Commission (FTC) challenged the merger of Nestlé Holdings, Inc. and Dreyer's Grand Ice Cream, Inc., in the super-premium ice cream market, citing that "the market for super-premium ice cream is already highly concentrated, and this deal will reduce the number of significant competitors from three to two" and it would "lead to anticompetitive effects... including

\footnotetext{
${ }^{1}$ Product proliferation is not restricted to supermarket goods. It takes place in several product categories, such as sunglasses, apparel, watches, and consumer electronics. In most of these product categories, firms' product lines differ, not in quality, but in other features such as scent, color, or design, i.e., their products are horizontally differentiated.

${ }^{2}$ They said in a recent statement that Porsche will become another fully integrated brand of the Volkswagen group as of August 1, 2014.

${ }^{3}$ For additional examples see Froeb et al. (2007) or visit http://www.manufacturing.net/topics/mergersand-acquisitions.
} 
less product variety and higher prices". ${ }^{4}$

This paper studies the relationship between manufacturers mergers and product variety. A key novelty of our approach is that we consider a setting where manufacturers operate in a vertically related industry, i.e., in an industry where the production and the distribution of products take place at different industry levels. In such a setting, a manufacturers merger can affect not only the number of products offered in the market but also the terms of vertical trade which, in turn, can determine the efficiency of the downstream retailers and the final prices. Our purpose is to address a number of fundamental questions of both theoretical and practical importance, such as: How the introduction of new products is affected by the intensity of market competition? What is the relationship between product variety and the vertical contract terms? Whether and how a merger among manufacturers alters their product introduction decisions? Does a manufacturers merger harm consumers and total welfare?

To address the above, we construct a framework in which two upstream manufacturers produce initially two horizontally differentiated goods that they distribute to consumers through two competing multiproduct retailers. Manufacturers decide, first, whether or not they will merge, and second, they decide whether they will introduce additional product varieties into the market after incurring their respective fixed costs. Next, manufacturer(s) set the wholesale prices of their products and, in turn, the downstream retailers choose their quantities. In order to examine the role of vertical relations and the potential importance of accounting for them and for vertical trading in the analysis of the merger implications on product variety, we also analyze the benchmark case in which manufacturers operate in a one-tier market, i.e., they sell directly their products to consumers.

The introduction of a new product into the market gives rise to two opposite effects regardless of whether manufacturers have merged or not and of whether they operate in a vertically related market or in a one-tier market. First, it results into an increase in the market size. We refer to this positive effect as the market expansion effect. Second, it causes the appearance of intrabrand competition: a new product that a manufacturer introduces steals away - "cannibalizes" - demand from its already existing products. Clearly, this effect, the intrabrand competition effect, discourages new product introduction. When the

\footnotetext{
${ }^{4}$ Similar arguments were used also in decisions regarding the merger among Whole Foods Market and Wild Oats Market in the supermarket industry, the merger among Oracle and PeopleSoft in the software industry, and the merger of Kimberly-Clark Corp and H.J. Heinz Co. in the food industry.
} 
manufacturers remain separated, a third effect, an interbrand competition effect, which also discourages new product introduction is also in play. This effect corresponds to the increase in the competition among the two manufacturers that arises from the fact that a newly introduced product competes against the product(s) of the rival manufacturer.

We demonstrate that an important additional effect can emerge when the manufacturers do not sell directly their products to consumers: product introduction can decrease the wholesale prices. We refer to this as the wholesale pricing effect of new product introduction. The wholesale pricing effect is present only when the manufacturers are separated. When, instead, the manufacturers are merged, there is an "indifference result": the number of products has no effect on the wholesale prices. Intuitively, in the non-merger case, the introduction of additional products into the market implies that interbrand competition intensifies, and thus, the incentives of each manufacturer to behave more aggressively by lowering the wholesale prices of its product(s) get reinforced. This does not happen in the merger case since then the interbrand competition is fully internalized by the merged manufacturers.

Not surprisingly, we also demonstrate that the wholesale prices can be affected not only by product variety, but also by the structure of the upstream market. In particular, we find that an upstream merger causes an increase in the wholesale prices. Stated in other words, double marginalization is more severe when the merger materializes. This result holds independently of the number of products in the market and it is a straightforward implication of the fact that, as mentioned above, the merged manufacturers are able to internalize the externality that they would otherwise impose on each other by offering lower wholesale prices in order to promote their own products against their rival's products.

Importantly, our analysis reveals that a manufacturers merger can affect product variety in the market. In fact, we show that product variety can be higher when manufacturers are merged than when they are separated as long as products are sufficiently close substitutes and new product introduction is not too costly. Why is that? The intrabrand competition effect, which discourages product introduction, is stronger when the manufacturers are merged than when they are separated. This is so because while each separated manufacturer initially produces a single product, the merged manufacturers produce from the outset two products. At the same time though, the interbrand competition and the wholesale pricing effects, which also discourage product introduction, are present only when manufacturers are separated. Moreover, when products are not sufficiently close substitutes, there might be 
overinvestment in product introduction in the non-merger case because the manufacturers are trapped then into a prisoners' dilemma situation: while they would be better off if they could both commit not to expand their product lines, product introduction is a unilaterally dominant strategy, and thus, they both introduce a new variety into the market.

The presence of vertical relations is crucial for the emergence of the above mentioned product variety related merger induced efficiencies: in markets in which the manufacturers sell directly their products to consumers, product variety is never higher when the manufacturers are merged than when they are separated. This is so because in such markets, in contrast to what happens in vertically related markets, the manufacturers set themselves the quantities of the products. As a consequence, the wholesale prices, and thus, the double marginalization externality and the wholesale pricing effect are all absent in onetier markets. It follows from this that the exclusion of vertical relations in the analysis of manufacturers mergers could result into different conclusions regarding their implications.

A manufacturers merger, although it can enhance product variety in a vertically related market and increase the manufacturers profits, it hurts the downstream retailers and the consumers, and it reduces total welfare. In other words, the increase in the severeness of the double marginalization problem always dominates the merger's potential efficiency gains. Clearly, this suggests that the merger induced product variety synergies - its positive impact on product variety, cannot be used as an argument in favor of the merger in its evaluation by the antitrust authorities in cases in which the merger enhances significantly the market power.

Our prediction that a manufacturer merger can affect the number of products in the market seems to accord well with a number of empirical studies. In particular, Alexander (1997) and Watson (2009), studying respectively the music distribution industry and the eyewear retailing market, find a non-monotonic relationship between concentration and product variety. George (2007), instead, in her study of the U.S. daily newspapers market, concludes that more concentrated markets tend to have more variety both in terms of the number and of the variety of topics covered. Focusing on the issue of product variety in response to a merger, Berry and Waldfogel (2001) find that mergers in the U.S. radio broadcasting market prompted an increase in both variety per station and overall variety in the market. In contrast, according to Gotz and Gugler (2006) and Fan (2003) mergers in the Austrian gasoline market and in the U.S. daily newspapers market caused a decrease in their product variety. Summing up, the empirical literature documents the existence of a 
relationship between product variety and market structure and suggests that the assumption that a merger leaves product variety unaffected is questionable. This, in turn, suggests that the analysis of mergers in markets with differentiated products and multi-product firms that does not take into account the mergers' impact on product variety can be incomplete.

Although the empirical evidence indicates that mergers can affect product variety, the existing theoretical work on horizontal mergers has little to say about the relationship between mergers and product variety. The standard merger theory has focused almost exclusively on horizontal pricing effects (e.g., Reynolds et al., 1983, Davidson and Deneckere, 1985 ) and/or on cost related efficiencies (e.g., Farrell and Shapiro, 1988, Perry and Porter, 1985)..$^{5}$ A notable exception is the paper of Lommerud and Sorgard (1997) which studies how a merger affects firms' decisions regarding the expansion of their product lines. More specifically, Lommerud and Sorgard consider a market with three firms and differentiated products. They assume that each firm initially offers one product and that there is a fixed non-sunk cost of marketing a brand. They find that whenever a merger between two of the firms is profitable, it either has a negative impact or no impact at all on product variety and that it is often detrimental to welfare. When instead the merger triggers the introduction of a new product by the outsider, and thus, causes an increase in product range, the merger is unprofitable. Another exception is a recent paper by Chen and Schwartz (2013). ${ }^{6}$ In contrast to Lommerud and Sorgard (1997), Chen and Schwartz (2013) consider mergers to monopoly and assume that initially only a single product is offered by all the market participants. They find that when product introduction is sufficiently non-drastic, the incentives to innovate are stronger when the merger takes place, and subsequently, that consumer welfare and overall welfare can then be higher under monopoly than under other more rivalrous regimes. ${ }^{7}$ Importantly, all the above mentioned papers consider only one-tier markets. Therefore, in contrast to us, they do not take into account the fact that product

\footnotetext{
${ }^{5}$ We should note that there exists a vast theoretical literature on the product line decisions of competing firms (see, e.g., Brander and Eaton, 1984, Raubitschek, 1987, Martínez-Giralt and Neven, 1988, Gilbert and Matutes, 1993, De Fraja, 1993, Dobson and Waterson, 1996, Avenel and Caprice, 2006, Gandhi et al. 2008). However, this literature does not examine the impact of market structure changes on these decisions. Moreover, there is an extensive theoretical literature on product variety driven not by product proliferation but by firms' market entry decisions (see e.g., Salop, 1979, Schmalensee, 1978, Lancaster, 1979, Eaton and Lipsey, 1979 and Innes, 2008).

${ }^{6}$ Greenstain and Ramey (1998) analyze a similar topic in a vertical product differentiation framework.

${ }^{7}$ Note that there is a number of papers (see e.g., Gandhi et al., 2008 and Mazzeo et al., 2012) which examine how a horizontal merger can affect product variety not though through altering the number of products but through altering the product characteristics. In other words, they examine whether post-merger, the merged firm has incentives to reposition its products in terms of their degree of product differentiation.
} 
manufacturers often do not sell directly their products to consumers and, by not doing so, clearly, they do not explore the role of vertical relations and trading for the merger implications on product variety.

Our paper contributes to the recently growing literature on horizontal mergers in vertically related industries. Horn and Wolinsky (1988), Ziss (1995), O'Brien and Shaffer (2003), Inderst and Wey (2003), Froeb et al. (2007), Milliou and Petrakis (2007) and Milliou and Pavlou (2013), similarly to us, study mergers in the upstream market. ${ }^{8}$ Within this literature, only Milliou and Pavlou (2013), in line with us, analyze the potential efficiency gains of upstream mergers. However, Milliou and Pavlou (2013) do so considering a market with exclusive relations pre-merger and cost-related efficiency gains. We complement their work by using a less restrictive market structure, and importantly, by analyzing the product variety related efficiency gains of upstream mergers. The only papers that, to the best of our knowledge, do consider product variety issues within the literature on horizontal mergers in vertically related industries are the papers by Inderst and Shaffer (2007) and Faulí-Oller (2008), which focus though on downstream mergers and not on upstream mergers. Both of these papers demonstrate that a merger among retailers allows them to commit not to sell one of the goods supplied by manufacturers, and thus, that such a merger can result into a welfare-detrimental decrease in product variety. These papers differ from ours not only because of their different focus, but also because in their setting there is no product introduction; the number of products manufactured by the upstream firms is exogenous and the downstream firm(s) choose how many of them they will distribute. ${ }^{9,10}$

The rest of the paper has the following structure. In Section 2, we describe our model. In Section 3, we perform the equilibrium analysis. In Section 4, we examine the implications

\footnotetext{
${ }^{8}$ Berry and Waldfogel (2001), von Ungern-Sternberg (1996), Dobson and Waterson, (1997), Inderst and Wey (2003) and (2011), Lommerud et al. (2005), Fauli-Oller and Bru (2008), Symeonidis (2008) and (2010), Fauli-Oller et al. (2011), Faulí-Oller (2008), Faulí-Oller and Sandonís (2014) and Inderst and Shaffer (2007), study, instead, downstream mergers.

${ }^{9}$ In a related paper, Milliou, Petrakis and Sloev (2010), similarly to us, endogenize upstream product innovation. However, they focus on the role played by the economies of scope and upstream entry and not by the upstream mergers.

${ }^{10}$ Our work is also related to the literature that endogenizes the distribution systems that arise when there is market power at both the manufacturing and the retailing levels (see e.g., O'Brien and Shaffer, 1997, Bernheim and Whinston, 1998, Lin, 1990, O'Brien and Shaffer, 1993, Chang, 1992, Moner-Colonques et al., 2004 and 2011 and Mauleon et al., 2011). In our paper, in contrast to this literature, we take as given the distribution system, in the sense that we assume that retailers are multiproduct firms that distribute all the varieties produced upstream, and focus instead on manufacturers mergers and on manufacturers incentives to invest in product innovation. This is not a restrictive assumption however. Moner-Colonqués et al. (2011) show, in a similar setting, that retailers would choose to overlap their product lines whenever their retail margins are not too asymmetric.
} 
of merger on the wholesale prices and product variety. In Section 5, we explore the merger incentives and its impact on retailers, consumers and welfare. In Section 6, we discuss the role of vertical relations. In Section 7, we enrich our analysis by considering what happens when the merger does not lead to monopoly. Finally, in Section 8, we conclude.

\section{The Model}

We consider a market consisting of two upstream product manufacturers, $M_{1}$ and $M_{2}$, and two downstream retailers, $R_{1}$ and $R_{2}$. Each $M_{i}$, with $i=1,2$, initially produces a singleproduct at zero marginal cost, but it can increase the number of its products by investing in new product introduction. ${ }^{11}$ In particular, each $M_{i}$ can introduce an additional product variety after incurring a fixed cost, $F>0$. Depending on the manufacturers product introduction decisions, the total number of products in the market, $N$, will be two, three or four, i.e., $N \in\{2,3,4\}$.

Each $R_{k}$, with $k=1,2$, sells to the final consumers all the products of the two manufacturers after paying the per unit wholesale price, $w_{n}$, for each product $n$, with $n \in\{1,2,3,4\}$, to its respective manufacturer. Moreover, $R_{k}$ and $R_{l}$ face a continuum of identical consumers. Following Singh and Vives (1984), we assume that the representative consumer has a quadratic utility function which is separable in income and it is given by:

$$
u\left(Q_{1}, \ldots, Q_{N}, I\right)=a \sum_{n=1}^{N} Q_{n}-\frac{1}{2}\left(\sum_{n=1}^{N} Q_{n}^{2}+2 \gamma \sum_{n \neq j} Q_{n} Q_{j}\right)+I,
$$

where $Q_{n}$ denotes the total quantity of good $n$ sold in the market and $I$ stands for consumer's income. From the utility maximization program we directly obtain the following (inverse) demand function faced by $R_{k}$ for each product $n$ :

$$
p_{n k}\left(q_{n k}, q_{n l}, Q_{-n}\right)=a-q_{n k}-q_{n l}-\gamma\left(Q_{-n}\right),
$$

where $p_{n k}$ and $q_{n k}$ are respectively the price and the quantity of product $n$ sold by $R_{k}, q_{n l}$ is the quantity of the same product sold by the rival retailer $R_{l}$, with $k, l=1,2$ and $k \neq l$, and $Q_{-n}$ is the quantity of the rest of the product(s). ${ }^{12}$ The parameter $\gamma$, with $0<\gamma<1$,

\footnotetext{
${ }^{11}$ Note that we would obtain qualitatively similar results if we had assumed instead a positive and constant marginal production cost.

${ }^{12}$ It follows that $Q_{n}=q_{n k}+q_{n l}$.
} 
denotes the degree of product substitutability; namely, the higher is $\gamma$, the closer substitutes are the products of the manufacturers. ${ }^{13}$

Before introducing new products, the manufacturers can decide to merge among them. When they do so, clearly, a monopolist is created in the upstream market, denoted by $M .{ }^{14}$ The upstream monopolist can also invest in product introduction. More specifically, $M$ can increase the number of its products from two to three or four incurring the respective fixed cost $F$ for each additional product or it can restrict its product range by withdrawing one of the two already existing products. We assume that the fixed cost of introducing the two initial varieties is already sunk. This implies that the withdrawal of one of the two initial brands by the merged firm would not result into any fixed cost saving.

Firms play a four-stage game. In particular, in stage one, $M_{1}$ and $M_{2}$ decide whether or not they will merge. In stage two, if the merger has not taken place, each $M_{i}$ decides whether it will introduce a new product into the market. If the merger, instead, has taken place, the merged entity $M$ decides respectively how many products it will offer in the market. In stage three, the manufacturer(s) set the wholesale prices for each of their products. Finally, in stage four, the retailers choose the quantities of the products.

Our notational convention for the rest of the paper will be as follows. The first superscript, $M$ or $S$, will denote respectively whether the manufacturers have merged or remained separated and the second superscript will denote the total number or products in the market.

\section{Equilibrium Product Variety}

In the last stage of the game, independently of whether the manufacturers have merged or not, each $R_{k}$ chooses the quantity of each product, $q_{n k}$, in order to maximize its profits which are given by:

$$
\Pi_{R_{k}}=\sum_{n=1}^{N}\left[p_{n k}\left(q_{n k}, q_{n l}, Q_{-n}\right)-w_{n}\right] q_{n k} .
$$

\footnotetext{
${ }^{13}$ Note that the two retailers are not differentiated, i.e., consumers do not perceive differently a product sold at one retailer than at the other retailer. Note also that for the sake of simplificity $\gamma$ denotes the degree of product substitutability both among the products of different manufacturers and among the products of the same manufacturer.

${ }^{14}$ In Section 7, we extend our analysis to the case in which there are inititally 3 manufacturers in the upstream market and the merger takes place between just two of them, i.e., it does not create an upstream monopoly.
} 
Solving the system of first order conditions, we obtain the equilibrium quantities of each product $n$ sold by $R_{1}$ and $R_{2}, q_{n 1}\left(w_{n}, w_{-n}\right)$ and $q_{n 2}\left(w_{n}, w_{-n}\right)$ respectively. ${ }^{15}$ The total market demand for product $n$ is $Q_{n}=q_{n 1}\left(w_{n}, w_{-n}\right)+q_{n 2}\left(w_{n}, w_{-n}\right)$.

\subsection{Upstream Separated Firms and New Product introduction}

When $M_{1}$ and $M_{2}$ remain separated, there are three possible third-stage subgames depending on the number of products that they manufacture: (i) the "no product introduction" subgame where both $M_{1}$ and $M_{2}$ produce one product each, (ii) the "partial product introduction" subgame where $M_{1}$ produces two products and $M_{2}$ one, and (iii) the "full product introduction" subgame where both $M_{1}$ and $M_{2}$ produce two products each. ${ }^{16}$ Next, we analyze each subgame separately.

In the "no product introduction" subgame, $M_{1}$ and $M_{2}$ face respectively the following maximization problems:

$$
\underset{w_{1}}{\operatorname{Max}} \Pi_{M_{1}}=w_{1} Q_{1}\left(w_{1}, w_{2}\right) \text { and } \underset{w_{2}}{\operatorname{Max}} \Pi_{M_{2}}=w_{2} Q_{2}\left(w_{1}, w_{2}\right)
$$

Solving (1), we obtain the equilibrium wholesale prices:

$$
w_{1}^{S 2}=w_{2}^{S 2}=\frac{a(1-\gamma)}{2-\gamma}
$$

In the "partial product introduction" subgame, the maximization problems of $M_{1}$ and $M_{2}$ are: $^{17}$

$$
\underset{w_{1}, w_{3}}{\operatorname{Max}} \Pi_{M_{1}}=w_{1} Q_{1}\left(w_{1}, w_{2}, w_{3}\right)+w_{3} Q_{3}\left(w_{1}, w_{2}, w_{3}\right) \text { and } \underset{w_{2}}{\operatorname{Max}} \Pi_{M_{2}}=w_{2} Q_{2}\left(w_{1}, w_{2}, w_{3}\right)
$$

The resulting equilibrium wholesale prices are:

$$
w_{1}^{S 3}=w_{3}^{S 3}=\frac{a\left(2+\gamma-3 \gamma^{2}\right)}{4+2 \gamma(2-\gamma)} \text { and } w_{2}^{S 3}=\frac{a\left(1-\gamma^{2}\right)}{2+\gamma(2-\gamma)}
$$

It is easy to see that $w_{1}^{S 3}>w_{2}^{S 3}$. That is, the multi-product manufacturer charges higher

\footnotetext{
${ }^{15}$ The exact expressions are included in the Appendix.

${ }^{16}$ There is a fourth subgame in which $M_{1}$ produces one product and $M_{2}$ produces two products. However, the analysis for this subgame is the same as the one for the subgame in which $M_{1}$ produces two products and $M_{2}$ one, with the roles of $M_{1}$ and $M_{2}$ reversed.

${ }^{17}$ Note that we implicitly assume in this case that products 1 and 3 are manufactured by $M_{1}$ and product 2 by $M_{2}$.
} 
wholesale prices than its single-product rival.

Finally, in the "full product introduction" subgame, the manufacturers solve the following:

$$
\begin{aligned}
& \underset{w_{1}, w_{3}}{\operatorname{Max}} \Pi_{M_{1}}=w_{1} Q_{1}\left(w_{1}, w_{2}, w_{3}, w_{4}\right)+w_{3} Q_{3}\left(w_{1}, w_{2}, w_{3}, w_{4}\right) ; \\
& \underset{w_{2}, w_{4}}{\operatorname{Max}} \Pi_{M_{2}}=w_{2} Q_{2}\left(w_{1}, w_{2}, w_{3}, w_{4}\right)+w_{4} Q_{4}\left(w_{1}, w_{2}, w_{3}, w_{4}\right) .
\end{aligned}
$$

From the solution of (5) and (6), we have:

$$
w_{1}^{S 4}=w_{3}^{S 4}=w_{2}^{S 4}=w_{4}^{S 4}=\frac{a(1-\gamma)}{2} .
$$

By comparing the equilibrium wholesale prices in the three different scenarios we find:

Proposition 1 When the upstream manufactures are separated, the equilibrium wholesale prices decrease with the total number of products in the market.

According to Proposition 1, when the upstream manufacturers are separated, the higher the number of products in the market, the lower the wholesale prices. The intuition for this finding is as follows. Both upstream manufacturers have incentives to behave aggressively and reduce their wholesale prices in order to favour the sales of their own products relative to the respective sales of their rival's products. Clearly, their incentives to do so are stronger when competition is more intense and competition is indeed more intense when the number of products in the market increases. In particular, when manufacturers produce one product each, there is only interbrand competition. But, when they introduce additional products, then not only interbrand competition is stronger, but also intrabrand competition is present. In what follows, we will refer to the negative impact that product introduction has on the wholesale prices when the upstream firms are separated as the wholesale pricing effect.

Next, we analyze each manufacturer's product introduction decision in stage two. There are three candidate second-stage equilibria, each of them corresponding to one of the subgames analyzed above. Substituting the equilibrium wholesale prices into each manufacturer's respective (gross from the cost of product introduction) profits in each subgame, and subtracting the respective fixed costs, we note that under "full product introduction" manufacturer's profits are negative unless product introduction is not too costly, and in particular, unless $F<\bar{F}^{S}(\gamma) \equiv \frac{a^{2}(1-\gamma)(2+3 \gamma)^{2}}{3(1+2 \gamma)[2+2 \gamma(2-\gamma)]^{2}}$. Taking this into account, we check for possible deviations from each of the candidate equilibrium and we find the following: 
Proposition 2 When the upstream manufacturers are separated and $F<\bar{F}^{S}(\gamma)$, there exist $F_{1}^{S}(\gamma)$ and $F_{2}^{S}(\gamma)$, with $\bar{F}^{S}(\gamma)>F_{1}^{S}(\gamma)>F_{2}^{S}(\gamma)$, such that the unique equilibrium is

(i) no product introduction $(N=2)$ when $\gamma>0.9164$ for all $F$, as well as when $\gamma<$ 0.9164 if $F>F_{1}^{S}(\gamma)$,

(ii) partial product introduction $(N=3)$ when $0.8346<\gamma<0.9164$ if $F<F_{1}^{S}(\gamma)$, as well as when $\gamma<0.8346$ if $F_{2}^{S}(\gamma)<F<F_{1}^{S}(\gamma)$,

(iii) full product introduction $(N=4)$ when $\gamma<0.8346$ if $F<F_{2}^{S}(\gamma)$.

The introduction of new products into the market gives rise to four main effects. First, there is a market expansion effect which corresponds to the increase in the market size/demand caused by the introduction of an additional product variety. Clearly, this effect encourages new product introduction. Second, there is an intrabrand competition effect. This refers to the fact that when an upstream manufacturer extends its product range, its already existing product faces additional competition. In other words, the new product partly cannibalizes the demand for the existing product. This effect, in contrast to the market expansion effect, discourages new product introduction. The third effect is the interbrand competition effect which corresponds to the intensification of competition with the rival upstream manufacturer caused by new product introduction. It is straightforward that this effect also discourages new product introduction. Finally, the fourth effect is the wholesale pricing effect that we identified above (Proposition 1). This effect discourages the manufacturers' new product introduction incentives as well.

When products are sufficiently close substitutes, and thus, competition is tough, then as Proposition 2(i) informs us, there is no product introduction in equilibrium. This is so because the wholesale pricing effect, the intrabrand competition effect and the interbrand competition effect are very strong then and dominate the positive market expansion effect which, in contrast, is weaker then. Otherwise, and as long as product introduction is not too costly, the market expansion effect can dominate and result into product introduction. In fact, when neither products are too close substitutes nor product introduction is too costly, both upstream firms extend their product lines in equilibrium (Proposition 2(iii)). But, it is important to note that when they do so, they are trapped into a prisoner's dilemma situation (i.e., they would be better off if none of them innovated), unless products are sufficiently differentiated and the cost of product introduction is very low. The prisoner's dilemma situation arises because in the "partial product introduction" case, the 
non-innovating upstream firm has unilateral incentives to deviate and innovate as well, so that it expands its own market and steals away market share from its rival's products.

\subsection{Upstream Merger and New Product Introduction}

When the upstream manufacturers merge, the newly formed upstream monopolist solves, in stage three, the following:

$$
\underset{w_{1}, . ., w_{N}}{\operatorname{Max}} \Pi_{M}=\sum_{n=1}^{N} w_{n} Q_{n}\left(w_{n}, w_{-n}\right)
$$

where $N=2,3,4$ depending on its product introduction decision. From the first order conditions of (8), we find the equilibrium wholesale prices: $w_{n}^{M N}=\frac{a}{2}$ for $n \in\{1,2,3,4\}$ and $N \in\{2,3,4\}$. Two important observations are in place. First, we note that the wholesale prices are independent of the degree of product differentiation. And second, we note that they are also independent of the total number of products in the market. Thus, there is an "indifference result": the upstream multi-product monopolist's pricing decisions do not depend on the number of its products. ${ }^{18}$

Remark 1 When the upstream manufactures are merged, the equilibrium wholesale prices are independent of the total number of products in the market.

In order to analyze the merged manufacturers' product introduction decision in stage two, first, we substitute $w_{n}^{M N}$ into its respective (gross from the cost of product introduction) profits (8), and then, we subtract the associated fixed cost(s) of product introduction from them. Doing so, we note that we need to assume that $F<\bar{F}^{M} \equiv \frac{a^{2}}{2+4 \gamma}$, in order to make sure that $M$ 's profits are positive in all cases under consideration. Finally, comparing $\Pi_{M}^{M 2}$, $\Pi_{M}^{M 3}$ and $\Pi_{M}^{M 4}$, we reach the following conclusion:

Proposition 3 When the upstream manufacturers are merged and $F<\bar{F}^{M}(\gamma)$, there exist $F_{1}^{M}(\gamma)$ and $F_{2}^{M}(\gamma)$, which decrease in $\gamma$ and satisfy $F_{1}^{M}(\gamma)>F_{2}^{M}(\gamma)>\bar{F}^{M}(\gamma)$, such that the unique equilibrium is

(i) no product introduction $(N=2)$ if $F>F_{1}^{M}(\gamma)$,

\footnotetext{
${ }^{18}$ This result is somehow similar to the indifference result identified in the literature (see e.g., Petrakis and Dhillon, 2002) regarding the independence of the wholesale prices charged by a single-product upstream monopolist from the number of downstream firms.
} 
(ii) partial product introduction $(N=3)$ if $F_{2}^{M}(\gamma)<F<F_{1}^{M}(\gamma)$, and

(iii) full product introduction $(N=4)$ if $F<F_{2}^{M}(\gamma)$.

As Proposition 3 states, the upstream monopolist has incentives to invest in order to enlarge its product line unless the cost of doing so is too high $\left(F>F_{1}^{M}(\gamma)\right)$. In fact, when the cost of product introduction is sufficiently low $\left(F<F_{2}^{M}(\gamma)\right), M$ will introduce two, and not just one, additional products in the market. Intuitively, when the manufacturers merge, the interbrand competition effect of product introduction disappears. The same holds for the wholesale pricing effect (Remark 1). Hence, when the merged manufacturers make their product introduction decision, they are faced only with the following trade-off: by investing in product introduction, they expand their total demand (market expansion effect), but they cannibalize the demand for their already existing products (intrabrand competition effect). It turns out that the former effect, the market expansion effect, is stronger than the intrabrand competition effect. Therefore, when product introduction is not too costly, the upstream monopolist innovates. Notice that withdrawing one of the two products is never an optimal strategy for the merged firms. The reason is twofold: on the one hand, there would be no cost savings given our assumption that product introduction costs for the two already existing products is already sunk; on the other hand, the positive effect of a reduction in intrabrand competition cannot compensate the merged firm for the negative market contraction effect of withdrawing one of the two already existing products.

As Proposition 3 also states, the critical values of $F$ for product introduction decrease, when product substitutability increases. Thus, not surprisingly and in line with what happens in the non-merger case, the merged upstream firms have weaker product introduction incentives when products are closer substitutes. This is a straightforward implication of the fact that when products become closer substitutes, the intrabrand competition effect gets reinforced, i.e., a product tends to cannibalize more the firm's other product(s), and the market expansion effect gets weaker.

\section{Merger Implications on Wholesale Prices and Product Va- riety}

In this Section, we examine the implications of a manufacturers merger on the wholesale prices as well as on product variety. 
Starting with the wholesale prices and by direct comparison of the equilibrium values under both scenarios our main conclusion, included in Proposition 4 below, is that the manufacturers charge higher wholesale prices when they are merged than when they are separated. This result holds independently of the total number of products in the market. In other words, it holds even when there is less product introduction in the non-merger case than in the merger case. Intuitively, once the manufacturers merge, they stop competing among them. This, in turn, means that when they merge they are able to internalize the externality that they would otherwise impose on each other by offering lower wholesale price(s) for their own product(s) so that their downstream sales are increased.

Proposition 4 The wholesale prices are higher when the upstream firms are merged than when they are separated.

Combining Propositions 2 and 3, we are now able to evaluate the impact of an upstream merger on product variety.

Proposition 5 When the upstream firms are merged, product variety is higher than when they are separated (i) if $\gamma>0.8346$ and $F$ is not too high, (ii) if $0.693<\gamma<0.8346$ and $F$ is sufficiently low but not too low. Otherwise, when the upstream firms merge,product variety is either lower or equal to the one when they are separated.]]

The manufacturers merger affects product variety. In fact, according to Proposition 5 , product variety can be higher when the manufacturers merge than when they remain separated. This holds when products are not too differentiated and product introduction is not too costly. ${ }^{19}$

The intuition for the above result is as follows. As mentioned previously, the market expansion effect and the intrabrand competition effect are present both in the non-merger case and in the merger case. Instead, the wholesale pricing effect and the interbrand competition effect are present only in the non-merger case. In light of the negative impact that the two additional effects that exist only in the non-merger case have on the product introduction

\footnotetext{
${ }^{19}$ In fact, there are cases in which, while we have no product innovation in the non-merger case, we can have full innovation, and not only partial innovation in the merger case and the reverse. For instance, when $\gamma>0.9164$, the total number of products without the merger is always 2 while with the merger it is 3 if $F$ takes intermediate values and 4 if $F$ is sufficiently low. The detailed description for all the cases that arise in equilibrium and the specific conditions under which they hold are all available in the Appendix, in the proof of Proposition 5.
} 
incentives, one would expect that there would be less product variety then than when the merger materializes. But this is not so always for a number of reasons. The first reason is the prisoner's dilemma situation in which the manufacturers are trapped in the non-merger case when products are not too differentiated and product introduction is neither too costly nor too cheap - this situation results then into overinvestment in product introduction. The second reason has to do with the fact that the intrabrand competition effect is stronger when the manufacturers are merged than when they are not. This is so because product introduction increases the merged manufacturers' own products from two to three or even to four. Instead, when the manufactures are separated, product introduction can increase the products of a single manufacturer only from one to two. Since the intrabrand competition effect is stronger in the merger case, its negative impact on product introduction incentives is, in turn, also more severe then.

\section{$5 \quad$ Merger Incentives and Welfare Implications}

In what follows, we analyze the merger's impact on firms' profits, consumers' surplus and total welfare.

The merger allows the manufacturers to eliminate the interbrand competition, and thus, it removes the negative externality that they impose on each other. This, as we saw in Proposition 4, allows them to charge higher wholesale prices. Further, it allows them to coordinate their product introduction decisions, and thus, to avoid the prisoner's dilemma situation. In light of this, it is not surprising that, as Proposition 6(i) below states, an upstream merger always has a positive impact on upstream profits or, in other words, that merger incentives are always present.

\section{Proposition 6 An upstream merger:}

(i) increases the profits of the upstream firms,

(ii) decreases the profits of the downstream firms, consumers' surplus and total welfare.

In contrast to the upstream profits, the profits of the downstream retailers decrease when the merger materializes. Two forces drive this result. The first is the impact of product variety on downstream profits: downstream profits increase with product variety. This holds both in the merger and in the non-merger case and it is quite intuitive: when there are more products in the market, the market size increases, and thus, the sales and 
profits of the retailers also increase. ${ }^{20}$ The second force is the merger's impact on the wholesale prices: as we saw in Proposition 4, the downstream firms pay higher wholesale prices in the merger case than in the non-merger case. This force, clearly, decreases the merger's desirability from the downstream firms' viewpoint. The first force though works in the opposite direction, i.e., it works in favor of the upstream merger, when the goods are sufficiently close substitutes since the merger results then into more product variety (Proposition 5). But when goods are close substitutes, competition downstream is strong; hence, the positive market expansion effect of the introduction of additional goods into the market is weak; hence, the first force dominates.

What about the merger's impact on consumers' surplus? According to Proposition 6(ii), the merger always reduces consumers' surplus. This result is driven by similar forces to the ones analyzed above. More specifically, an increase in product variety benefits the consumers since their utility function is characterized by a preference for variety feature. At the same time though, an increase in the wholesale prices hurts the consumers since it translates into higher final prices (double marginalization). As we saw above, an upstream merger always leads to higher wholesale prices, and thus, it hurts the consumers through this channel. This effect is stronger than the merger's positive impact on product variety which is relatively weak because it emerges only when products are very close substitutes.

The merger's negative impact on consumers' surplus and downstream profits outsets its positive impact on the upstream profits. As a result, the merger is always detrimental for total welfare (Proposition 6(ii)). Stated in other words, the anticompetitive unilateral effect of a "merger to monopoly" is so pronounced that it cannot be compensated by the potential merger generated efficiency gains when the latter correspond to enhanced product variety. On this basis, we could to claim that our paper provides a theoretical justification for the view expressed in the recent U.S. Horizontal Merger Guidelines (2010) according to which "efficiencies almost never justify a merger to monopoly or near-monopoly. Just as adverse competitive effects can arise along multiple dimensions of conduct, such as pricing and new product development, so too can efficiencies operate along multiple dimensions".

\footnotetext{
${ }^{20}$ In the non-merger case, there is an additional reason for which retailers are better off when there is more product variety: the wholesale pricing effect that translates into increased downstream efficiency when there are more products.
} 


\section{The Role of Vertical Relations}

In this Section, we explore the role of vertical relations for the merger's implications. In order to do so, first, we analyze briefly what happens in the absence of vertical relations, i.e., in an one-tier market where product manufacturers sell directly their products to the consumers, and then, we compare our results with the ones in the presence of vertical relations.

In a one-tier market, stage three does not exist, i.e., the wholesale prices are zero by assumption, and the quantities are chosen directly by the product manufacturer(s). In such a market, we find that, similarly to what happens in a vertically related market, the merged firm never withdraws one of its already existing products from the market. Importantly, we find that a merger in a one-tier market never enhances product variety (Proposition 7(i)). This finding is mainly driven by the fact that in a one-tier market, the manufacturers set the quantities of their products and not the wholesale prices. As a result, the wholesale pricing effect which decreases the incentives of the separated manufacturers to introduce additional products into the market is present only in a vertically related market and not in a one-tier market.

Proposition 7 In a one-tier market, a merger:

(i) decreases product introduction when $F$ takes intermediate values; otherwise, it does not have any effect on product introduction,

(ii) increases profits, and

(iii) decreases consumers' surplus and total welfare.

Independently of whether a merger in a one-tier market has no effect or a negative effect on product variety, since the merger results into monopoly, it is not surprisingly that it is always profitable too (Proposition 7(ii)). Moreover, a straightforward implication of the decreased product variety and increased market power under merger, is that the merger in a one-tier market is harmful to consumers and to welfare (Proposition 7(iii)). Therefore, independently of the merger's impact on product variety, we conclude that a manufacturers merger to monopoly, either in a one-tier market or in a vertically related market, is always welfare-detrimental.

Having already examined the implications of a merger in one-tier market, we examine next how the existence of vertical relations itself affects product variety, for a given number 
of product manufacturers.

Proposition 8 Product variety in a one-tier market is either higher or equal to product variety in a two-tier market. This holds when manufacturers remain separated as well as when they merge.

Proposition 8 informs us that in markets with vertical relations, there is less or equal product variety than in markets without vertical relations. This holds when there is just one product manufacturer in the market as well as when there are two of them. This finding is mainly driven by the fact that in one-tier markets, the manufacturers set themselves the quantities of their products. This, in turn, implies that in one-tier markets the double marginalization externality is absent - there are no additional distortions. Therefore, the product manufactures obtain the whole surplus that it is generated by the production of their goods and by product introduction. Clearly, this is not the case in a vertically related market, where the retailers get part of the surplus and double marginalization is present. Given this, it follows that in a one-tier market, the return of an investment in product introduction is higher for the manufacturer than it is in a vertically related market.

It follows from the above that the consideration of vertical relations is of significant importance. The presence of vertical relations crucially affects the incentives for new product introduction, and in turn, affects the merger's implications. If we did not take vertical relations into account we would reach the conclusion that a merger always restricts product variety. In contrast, by allowing for such relations, we can conclude that, under certain conditions, a merger can enhance, instead of decrease, product variety.

\section{Extension: 3 Upstream Firms}

In this Section, we explore whether the manufacturers merger's negative impact on social welfare obtained so far is driven by our simplifying assumption of a duopolistic upstream market that allows us to consider only mergers to monopoly. In order to do so, we extend our main model to the case in which pre-merger there are three, instead of two, upstream manufacturers. As before, manufacturers can invest in product introduction, so each $M_{i}$, $i=1,2,3$ can introduce an additional product variety after incurring a fixed cost, $F>0$. This implies that in absence of a merger we can have now 3, 4, 5 or 6 products in the market. In the case of a merger, we consider only a merger among two out of the three manufacturers. 
In this case, the merged entity, $M$, decides whether it will continue producing the two initial products, it will withdraw one of its two products or it will invest in product introduction and increase the number of its varieties to three or four. That is, after a 2-firms merger we can have $2,3,4,5$ or 6 goods in the market.

Given that the complete resolution of this extended model is cumbersome and for the sake of simplicity in the exposition, we will describe the main results and the differences of this extended model with respect to the main model. ${ }^{21}$

Adding a third manufacturer is interesting because it allows to analyze the effect of a manufacturers merger not only on the merged firms incentives to alter the product range but also on the outsider's incentives to do the same. In contrast with the previous model, in this extended model, the existence of interbrand competition post-merger reduces the merged firms' incentives to add new varieties to the market. Indeed, we get that whereas in the 2 manufacturers setting and for close enough substitute goods, a merger could lead the merged entity to increase the number of varieties, in a 3 manufacturers setting, a 2-firms merger never leads the merging firms to increase the number of varieties. Indeed, it can be shown that for close enough substitutes $(\gamma>0.91)$, it could lead them to withdraw one of the two varieties that were already produced before the merger (this never occurs in the main model). The explanation for the latter result is just the existence of interbrand competition post-merger, which reduces upstream firms' incentives to invest in product introduction, especially when the goods are close substitutes: in this latter case, the reduction of interbrand competition produced by the withdrawal of one of the already existing brands may compensate the merging firms for the reduction in sales (notice that this occurs even if there is no fixed cost saving, given that the fixed cost of the initially produced brand is assumed to be already sunk).

On the other hand and not surprisingly, by reducing interbrand competition, the merger leads to an increase in the equilibrium wholesale prices, which hurts downstream firms (and consumers). This implies that the only way for a merger to be welfare enhancing in this setting would be through a positive effect on variety. We do find a region (for very differentiated products $(\gamma<0.39)$ and intermediate values of the fixed cost $F$ ) where a 2 -firms merger increases total variety (and social welfare). But, interestingly, this increase in variety is not caused by the merged firm; it is the non-merging firm who responds

\footnotetext{
${ }^{21}$ The detailed analysis is available from the authors upon request.
} 
aggressively to the merger by adding one more variety. And, as it is intuitive to understand, this merger is not profitable for the merging firms so it will not take place (this is another difference with the main model, where the manufacturers merger is always profitable). Lommerud and Sorgard (1997) find a similar result in their setting with a one tier industry and three firms.

Apart from this particular region, as long as the fixed cost $F$ of introducing a new variety is not too large, the merger always leads to less variety compared with the no merger case. Of course, for sufficiently large values of $F$ and regardless of the degree of product differentiation, we find a region where there would be no product introduction in both the merger and no merger cases. So we can conclude that in the extended setting with three producers, any profitable merger must reduce consumer surplus and social welfare (because it increases the wholesale prices (which translate into higher final prices) and it does not increase variety in the market).

Summarizing, the comparison between the two models seems to suggest that adding more manufacturers goes in the direction of reducing the merged firms' incentives to add new varieties after the merger due to increased competition, which makes difficult to find welfare improving mergers. On the other hand, talking about merger profitability, whereas in the setting with two manufacturers an upstream merger is always profitable, in the extended setting we can find unprofitable mergers, the reason being always an aggressive response by the outsider firm that reacts to the merger by adding a new brand.

\section{Concluding Remarks}

We have investigated the new product introduction incentives of competing manufacturers and how they are affected by a merger among them. We have taken into account the fact that most product manufacturers instead of selling their products to consumers directly, they sell them through multi-product retailers. In such a setting, a merger among product manufacturers can change not only the upstream market structure but also the trading with the downstream retailers. Both of these changes can, in turn, affect the incentives of manufacturers to expand their product lines.

We have found that the wholesale prices can be affected both by the number of products in the market and by the upstream market structure. In particular, as the number of products in the market increases, and thus, market competition intensifies, the whole- 
sale prices decrease when the manufacturers are separated but not when they are merged. Furthermore, when the manufacturers are merged, they internalize the negative interbrand competition externality that they impose on each other in the absence of a merger, and as a result, they charge higher wholesale prices than when they are separated.

We have also found that the equilibrium number of products, and thus, the product variety in the market can be affected both by whether or not the manufacturers merge and by the existence of vertical relations. More specifically, we have found that a manufacturers merger can cause an increase, instead of a decrease, in total product variety. This holds when the cost of product introduction is not too high and the goods are close enough substitutes since then, in the non-merger case, the negative impact of the interbrand competition is very pronounced and the manufacturers are trapped into a prisoners' dilemma situation. The merger generated product variety efficiencies though arise only when vertical relations are present. When, instead, the manufacturers sell directly their products to consumers and thus they do not suffer from the double marginalization externality, a merger among them never results into more product variety.

Our paper has added value to the literature on horizontal mergers by examining the mergers' potential product variety related efficiencies. We have pointed out that although an upstream merger could give rise to such efficiency gains, these efficiency gains are not strong enough to overturn its negative impact on consumers and total welfare through the increased wholesale prices. Stated in different words, we have provided a theoretical justification for the view expressed in the recent U.S. Horizontal Merger Guidelines (2010) according to which "efficiencies almost never justify a merger to monopoly or near-monopoly. Just as adverse competitive effects can arise along multiple dimensions of conduct, such as pricing and new product development, so too can efficiencies operate along multiple dimensions." We have shown that this anticompetitive aspect of manufacturers mergers holds even when there are more firms in the upstream market because the increased level of interbrand competition reduces the merged manufacturers' incentives to introduce new varieties into the market. We have also pointed out that the incorporation of vertical relations in the analysis could be critical for the evaluation of the merger's implications.

We should stress that our paper constitutes just a first step in the direction of understanding the relation between manufacturer mergers and product variety. In a following 
step, one could examine the role of alternative contract types, such as two-part tariffs. ${ }^{22}$ Moreover, one could also explore how the downstream market structure influences the manufacturers merger's impact on product variety or it could incorporate economies of scale in the analysis. These extensions are left for future research.

\section{Appendix}

\section{Third stage equilibrium outputs}

The equilibrium quantities obtained after solving the last stage of the game for given wholesale prices are:

(i) when $N=2$ :

$$
\begin{aligned}
& q_{11}\left(w_{1}, w_{2}\right)=q_{12}\left(w_{1}, w_{2}\right)=\frac{a(1-\gamma)-w_{1}+\gamma w_{2}}{3\left(1-\gamma^{2}\right)} \\
& q_{21}\left(w_{1}, w_{2}\right)=q_{22}\left(w_{1}, w_{2}\right)=\frac{a(1-\gamma)-w_{2}+\gamma w_{1}}{3\left(1-\gamma^{2}\right)}
\end{aligned}
$$

(ii) when $N=3$ :

$$
\begin{aligned}
& q_{11}\left(w_{1}, w_{2}, w_{3}\right)=q_{12}\left(w_{1}, w_{2}, w_{3}\right)=\frac{a(1-\gamma)-(1+\gamma) w_{1}+\gamma\left(w_{2}+w_{3}\right)}{3(1-\gamma)-6 \gamma^{2}} \\
& q_{21}\left(w_{1}, w_{2}, w_{3}\right)=q_{22}\left(w_{1}, w_{2}, w_{3}\right)=\frac{a(1-\gamma)-(1+\gamma) w_{2}+\gamma\left(w_{1}+w_{3}\right)}{3(1-\gamma)-6 \gamma^{2}} \\
& q_{31}\left(w_{1}, w_{2}, w_{3}\right)=q_{32}\left(w_{1}, w_{2}, w_{3}\right)=\frac{a(1-\gamma)-(1+\gamma) w_{3}+\gamma\left(w_{1}+w_{2}\right)}{3(1-\gamma)-6 \gamma^{2}}
\end{aligned}
$$

\footnotetext{
${ }^{22}$ We should note that serious complications arise in situations in which rival upstream firms trade through non-linear contracts with the same competing downstream firms. As mentioned in a review article by Miklos-Thal et al. (2010, p.345) "The formal modeling of such "interlocking" vertical relations has proved difficult... and we still know relatively little about many basic questions... Interlocking relationships cause modeling issues such as either the inexistence or a large multiplicity of equilibria even in simple competition games." Also, Inderst (2010, p. 343) states that "... the benchmark model where competing upstream firms simultaneously make take-it-or-leave-it offers to competing downstream firms, may fail to have an equilibrium in pure strategies."
} 
(iii) when $N=4$ :

$$
\begin{aligned}
& q_{11}\left(w_{1}, w_{2}, w_{3}, w_{4}\right)=q_{12}\left(w_{1}, w_{2}, w_{3}, w_{4}\right)=\frac{a(1-\gamma)-(1+2 \gamma) w_{1}+\gamma\left(w_{2}+w_{3}+w_{4}\right)}{3(1-2 \gamma)-9 \gamma^{2}} \\
& q_{21}\left(w_{1}, w_{2}, w_{3}, w_{4}\right)=q_{22}\left(w_{1}, w_{2}, w_{3}, w_{4}\right)=\frac{a(1-\gamma)-(1+2 \gamma) w_{2}+\gamma\left(w_{1}+w_{3}+w_{4}\right)}{3(1-2 \gamma)-9 \gamma^{2}} \\
& q_{31}\left(w_{1}, w_{2}, w_{3}, w_{4}\right)=q_{32}\left(w_{1}, w_{2}, w_{3}, w_{4}\right)=\frac{a(1-\gamma)-(1+2 \gamma) w_{3}+\gamma\left(w_{1}+w_{2}+w_{4}\right)}{3(1-2 \gamma)-9 \gamma^{2}} \\
& q_{41}\left(w_{1}, w_{2}, w_{3}, w_{4}\right)=q_{42}\left(w_{1}, w_{2}, w_{3}, w_{4}\right)=\frac{a(1-\gamma)-(1+2 \gamma) w_{4}+\gamma\left(w_{1}+w_{2}+w_{3}\right)}{3(1-2 \gamma)-9 \gamma^{2}} .
\end{aligned}
$$

\section{Proof of Proposition 2}

Just by plugging the third stage equilibrium wholesale prices into the manufacturers profit functions in the three different sub-games we get:

$$
\begin{aligned}
\Pi_{M_{1}}^{S 2} & =\Pi_{M_{2}}^{S 2}=\frac{2 a^{2}(1-\gamma)}{3(1+\gamma)(2-\gamma)^{2}} . \\
\Pi_{M_{1}}^{S 3} & =\frac{a^{2}(1-\gamma)(2+3 \gamma)^{2}}{3(1+2 \gamma)(2+(2-\gamma) \gamma)^{2}} ; \Pi_{M_{2}}^{S 3}=\frac{2 a^{2}(1-\gamma)(1+\gamma)^{3}}{3(1+2 \gamma)(2+(2-\gamma) \gamma)^{2}} . \\
\Pi_{M_{1}}^{S 4} & =\Pi_{M_{2}}^{S 4}=\frac{a^{2}\left(1-\gamma^{2}\right)}{3+9 \gamma} .
\end{aligned}
$$

A necessary condition for "partial product introduction" (three goods) to be an equilibrium is that $F \leq \bar{F}^{S}(\gamma)=\Pi_{M_{1}}^{S 3}=\frac{a^{2}(1-\gamma)(2+3 \gamma)^{2}}{3(1+2 \gamma)(2+(2-\gamma) \gamma)^{2}}$.

A necessary condition for "full product introduction" (four goods) to be an equilibrium is that $F \leq \overline{\bar{F}}^{S}(\gamma)=\Pi_{M i}^{S 4}=\frac{a^{2}\left(1-\gamma^{2}\right)}{3+9 \gamma}, \mathrm{i}=1,2$.

When is "no introduction" an equilibrium? The only possible deviation by, let's say, M1 is to "partial product introduction". Now, if $F>\bar{F}^{S}(\gamma)$, then such incentives do not exist. If $F \leq \bar{F}^{S}(\gamma)$, M1 deviates only if $\Pi_{M_{1}}^{S 3}-F \geq \Pi_{M_{1}}^{S 2}$. This is satisfied as long as $F \leq F_{1}^{S}(\gamma)$, where $F_{1}^{S}(\gamma)=\frac{a^{2}(1-\gamma)}{3}\left(\frac{(2+3 \gamma)^{2}}{(1+2 \gamma)(2+(2-\gamma) \gamma)^{2}}-\frac{2}{(1+\gamma)(2-\gamma)^{2}}\right)$ and $F_{1}^{S}(\gamma)<\bar{F}^{S}(\gamma)<\bar{F}^{S}(\gamma)$. But it is direct to see that $F_{1}^{S}(\gamma)<0$ when $\gamma>0.9164$. So if $\gamma>0.9164$, no deviation is profitable and "no introduction" is an equilibrium. If $\gamma \leq 0.9164$, however, "no introduction" is an equilibrium only if $F>F_{1}^{S}(\gamma)$.

When is "partial product introduction" an equilibrium? First of all, we know that it is not an equilibrium when $F>\bar{F}^{S}(\gamma)$. Also when $F \leq \bar{F}^{S}(\gamma)$ and $\gamma>0.9164$, or when $\gamma \leq 0.9164$ and $F>F_{1}^{S}(\gamma)$. When $\gamma \leq 0.9164$ and $F \leq F_{1}^{S}(\gamma)$, the possible deviation is for M2 to produce 2 goods instead of 1 good. This deviation is profitable for M2 as long as $\Pi_{M_{2}}^{S 4}-F \geq \Pi_{M_{2}}^{S 3}$, which holds if $F \leq F_{2}^{S}(\gamma)$, where $F_{2}^{S}(\gamma)=\frac{a^{2}(1-\gamma)(2+3 \gamma)^{2}}{3(1+\gamma(5+6 \gamma))(2+(2-\gamma) \gamma)^{2}}$ and $F_{1}^{S}(\gamma)>F_{2}^{S}(\gamma)$. But it is direct to see that $F_{2}^{S}(\gamma)<0$ when $\gamma>0.8346$. So if $0.8346<\gamma \leq 0.9164$, this deviation is not profitable and "partial product introduction" is 
an equilibrium. Finally, if $\gamma \leq 0.8346$ and $F>F_{2}^{S}(\gamma)$, "partial product introduction" is also an equilibrium.

When is "full introduction" an equilibrium? It is not an equilibrium when $F>\overline{\bar{F}}^{S}(\gamma)$. When $F \leq \overline{\bar{F}}^{S}(\gamma)$, the only possible deviation is for M2 to produce 1 good instead of 2 goods. We know that this deviation is profitable for M2 as long as $\gamma>0.8346$, or when $\gamma \leq 0.8346$ and $F>F_{2}^{S}(\gamma)$. So, we conclude that "full introduction" is an equilibrium only when $\gamma \leq 0.8346$ and $F \leq F_{2}^{S}(\gamma)$.

\section{Proof of Proposition 3}

Just by plugging the third stage equilibrium wholesale prices into the manufacturers profit functions in the three different sub-games we get:

$$
\Pi_{M}^{M 2}=\frac{a^{2}}{3+3 \gamma} ; \Pi_{M}^{M 3}=\frac{a^{2}}{2+4 \gamma} ; \Pi_{M}^{M 4}=\frac{2 a^{2}}{3+9 \gamma} .
$$

A necessary condition for "partial product introduction" to be an equilibrium is that $F \leq$ $\bar{F}^{M}(\gamma)=\Pi_{M}^{M 3}=\frac{a^{2}}{2+4 \gamma}$.

A necessary condition for "full product introduction" to be an equilibrium is that $F \leq$ $\overline{\bar{F}}^{M}(\gamma)=\Pi_{M}^{M 4}=\frac{2 a^{2}}{3+9 \gamma}$ with $\bar{F}^{M}(\gamma)<\overline{\bar{F}}^{M}(\gamma)$.

When is "no introduction" an equilibrium? It is always equilibrium when $F>\overline{\bar{F}}^{M}(\gamma)$. When $\bar{F}^{M}(\gamma)<F \leq \overline{\bar{F}}^{M}(\gamma)$ the only possible deviation by the merged firm is to "full introduction". If instead $F \leq \bar{F}^{M}(\gamma)$, there could be deviations to both "partial product introduction" and "full product introduction". If $F \leq \bar{F}^{M}(\gamma), M$ deviates to three goods as long as $\Pi_{M}^{M 3}-F \geq \Pi_{M}^{M 2}$. This is satisfied if $F \leq F_{1}^{M}(\gamma)$, where $F_{1}^{M}(\gamma)=\frac{a^{2}(1-\gamma)}{6\left(1+3 \gamma+2 \gamma^{2}\right)}$ and $F_{1}^{M}(\gamma)<\bar{F}^{M}(\gamma)$. On the other hand, $M$ deviates to four goods only if $\Pi_{M}^{M 4}-2 F \geq \Pi_{M}^{M 2}$. This is satisfied as long as $F \leq F_{3}^{M}(\gamma)$, where $F_{3}^{M}(\gamma)=\frac{a^{2}(1-\gamma)}{6\left(1+4 \gamma+3 \gamma^{2}\right)}$ and $F_{1}^{M}(\gamma)>F_{3}^{M}(\gamma)$. In short, "no introduction" is an equilibrium if and only if $F>F_{1}^{M}(\gamma)$.

When is "partial product introduction" an equilibrium? First of all, we know that it is not an equilibrium when $F>\bar{F}^{M}(\gamma)$. When $F \leq \bar{F}^{M}(\gamma)$, the possible deviation is for $\mathrm{M}$ to produce two goods or four goods instead of three goods. We know that a deviation to two goods is profitable for $\mathrm{M}$ as long as $F>F_{1}^{M}(\gamma)$. On the other hand, $\mathrm{M}$ deviates to four goods only if $\Pi_{M}^{M 4}-F \geq \Pi_{M}^{M 3}$. This is satisfied as long as $F \leq F_{2}^{M}(\gamma)$, where $F_{2}^{M}(\gamma)=\frac{a^{2}(1-\gamma)}{6(1+\gamma(5+6 \gamma)}$ with $F_{1}^{M}(\gamma)>F_{3}^{M}(\gamma)>F_{2}^{M}(\gamma)$. So summarizing, "partial product introduction" is an equilibrium if and only if $F_{2}^{M}(\gamma)<F \leq F_{1}^{M}(\gamma)$.

When is "full introduction" an equilibrium? It is not an equilibrium when $F>\overline{\bar{F}}^{M}(\gamma)$. When $\bar{F}^{M}(\gamma)<F \leq \overline{\bar{F}}^{M}(\gamma)$, the only possible deviation is for M to produce 2 goods 
instead of 4 goods, whereas if $F \leq \bar{F}^{M}(\gamma)$, the possible deviations are for M to produce two or three goods respectively. So, summarizing, "full introduction" is an equilibrium if and only if $F \leq F_{2}^{M}(\gamma)$ (recall that the ranking between the different relevant threshold values of $F$ is $F_{2}^{M}(\gamma)<F_{3}^{M}(\gamma)<F_{1}^{M}(\gamma)<\bar{F}^{M}(\gamma)<\overline{\bar{F}}^{M}(\gamma)$ and so $F \leq F_{2}^{M}(\gamma)$ also implies $\left.F \leq F_{3}^{M}(\gamma)\right)$.

Finally, it is direct to see that $F_{1}^{M}(\gamma), F_{2}^{M}(\gamma)$ and $\bar{F}^{M}(\gamma)$ are all decreasing in $\gamma$.

\section{Proof of Proposition 5}

Combining the results of Propositions 2 and 3 we can easily rank the different threshold values of $F$ in order to be able to compare the equilibrium number of varieties pre-merger and post-merger for different values of the product differentiation parameter $\gamma$.

It is direct to see that when $\gamma>0.9164$ we have $F_{2}^{S}(\gamma)<F_{1}^{S}(\gamma)<0<F_{2}^{M}(\gamma)<$ $F_{1}^{M}(\gamma)$, which implies that (i) for $F<F_{2}^{M}(\gamma)$, the merger upstream leads to more product introduction (4 varieties) compared with the pre-merger case (only two varieties); (ii) for $F_{2}^{M}(\gamma) \leq F<F_{1}^{M}(\gamma)$ the merger upstream leads to more product introduction (3 varieties) compared with the pre-merger case (only 2 varieties); finally, (iii) for $F \geq F_{1}^{M}(\gamma)$ the merger does not affect the number of varieties (2 goods in each case).

When $0.8415<\gamma<0.9164$ we have $F_{2}^{S}(\gamma)<0<F_{1}^{S}(\gamma)<F_{2}^{M}(\gamma)<F_{1}^{M}(\gamma)$, which implies that (i) for $F<F_{1}^{S}(\gamma)$, the merger upstream leads to more product introduction (4 varieties) compared with the pre-merger case (only 3 varieties); $F_{1}^{S}(\gamma) \leq F<F_{2}^{M}(\gamma)$, the merger upstream leads to more product introduction (4 varieties) compared with the pre-merger case (only 2 varieties); (iii) for $F_{2}^{M}(\gamma) \leq F<F_{1}^{M}(\gamma)$ the merger upstream leads to more product introduction (3 varieties) compared with the pre-merger case (only 2 varieties); finally, (iv) for $F \geq F_{1}^{M}(\gamma)$ the merger does not affect the number of varieties (2 goods in each case).

When $0.8346<\gamma<0.8415$ we have $F_{2}^{S}(\gamma)<0<F_{2}^{M}(\gamma)<F_{1}^{S}(\gamma)<F_{1}^{M}(\gamma)$, which implies that (i) for $F<F_{2}^{M}(\gamma)$, the merger upstream leads to more product introduction (4 varieties) compared with the pre-merger case (only 3 varieties); (ii) for $F_{2}^{M}(\gamma) \leq F<$ $F_{1}^{S}(\gamma)$ the merger does not affect the number of varieties (3 goods in each case); (iii) for $F_{1}^{S}(\gamma) \leq F<F_{1}^{M}(\gamma)$ the merger upstream leads to more product introduction (3 varieties) compared with the pre-merger case (only 2 varieties); finally, (iv) for $F \geq F_{1}^{M}(\gamma)$ the merger does not affect the number of varieties ( 2 goods in each case).

When $0.7261<\gamma<0.8346$ we have $0<F_{2}^{S}(\gamma)<F_{2}^{M}(\gamma)<F_{1}^{S}(\gamma)<F_{1}^{M}(\gamma)$, which 
implies that (i) for $F<F_{2}^{S}(\gamma)$ the merger does not affect the number of varieties (4 goods in each case); (ii) for $F_{2}^{S}(\gamma) \leq F<F_{2}^{M}(\gamma)$, the merger upstream leads to more product introduction (4 varieties) compared with the pre-merger case (only 3 varieties); (iii) for $F_{2}^{M}(\gamma) \leq F<F_{1}^{S}(\gamma)$ the merger does not affect the number of varieties (3 goods in each case); (iv) for $F_{1}^{S}(\gamma) \leq F<F_{1}^{M}(\gamma)$ the merger upstream leads to more product introduction (3 varieties) compared with the pre-merger case (only 2 varieties); finally, (v) for $F \geq F_{1}^{M}(\gamma)$ the merger does not affect the number of varieties (2 goods in each case).

When $0.6931<F<0.7261$ we have $0<F_{2}^{S}(\gamma)<F_{2}^{M}(\gamma)<F_{1}^{M}(\gamma)<F_{1}^{S}(\gamma)$, which implies that (i) for $F<F_{2}^{S}(\gamma)$ the merger does not affect the number of varieties (4 goods in each case); (ii) for $F_{2}^{S}(\gamma) \leq F<F_{2}^{M}(\gamma)$, the merger upstream leads to more product introduction (4 varieties) compared with the pre-merger case (only 3 varieties); (iii) for $F_{2}^{M}(\gamma) \leq F<F_{1}^{M}(\gamma)$ the merger does not affect the number of varieties (3 goods in each case); (iv) for $F_{1}^{M}(\gamma) \leq F<F_{1}^{S}(\gamma)$ the merger upstream leads to less product introduction (2 varieties) compared with the pre-merger case (3 varieties); finally, (v) for $F \geq F_{1}^{S}(\gamma)$ the merger does not affect the number of varieties (2 goods in each case).

When $0.4046<F<0.6931$ we have $0<F_{2}^{M}(\gamma)<F_{2}^{S}(\gamma)<F_{1}^{M}(\gamma)<F_{1}^{S}(\gamma)$, which implies that (i) for $F<F_{2}^{M}(\gamma)$ the merger does not affect the number of varieties (4 goods in each case); (ii) for $F_{2}^{M}(\gamma) \leq F<F_{2}^{S}(\gamma)$, the merger upstream leads to less product introduction (3 varieties) compared with the pre-merger case (4 varieties); (iii) for $F_{2}^{S}(\gamma) \leq F<F_{1}^{M}(\gamma)$ the merger does not affect the number of varieties (3 goods in each case); (iv) for $F_{1}^{M}(\gamma) \leq F<F_{1}^{S}(\gamma)$ the merger upstream leads to less product introduction (2 varieties) compared with the pre-merger case (3 varieties); finally, (v) for $F \geq F_{1}^{S}(\gamma)$ the merger does not affect the number of varieties ( 2 goods in each case).

When $F<0.4046$ we have $0<F_{2}^{M}(\gamma)<F_{1}^{M}(\gamma)<F_{2}^{S}(\gamma)<F_{1}^{S}(\gamma)$, which implies that (i) for $F<F_{2}^{M}(\gamma)$ the merger does not affect the number of varieties (4 goods in each case); (ii) for $F_{2}^{M}(\gamma) \leq F<F_{1}^{M}(\gamma)$, the merger upstream leads to less product introduction (3 varieties) compared with the pre-merger case (4 varieties); (iii) for $F_{1}^{M}(\gamma) \leq F<F_{2}^{S}(\gamma)$, the merger upstream leads to less product introduction (2 varieties) compared with the premerger case (4 varieties); (iv) for $F_{2}^{S}(\gamma) \leq F<F_{1}^{S}(\gamma)$, the merger upstream leads to less product introduction ( 2 varieties) compared with the pre-merger case (3 varieties); finally, (v) for $F \geq F_{1}^{S}(\gamma)$ the merger does not affect the number of varieties (2 goods in each case).

\section{Proof of Proposition 6}


In order to prove profitability of the manufacturers merger, we proceed by comparing the post-merger upstream profits with the sum of the pre-merger upstream firms' profits for each possible combination of (equilibrium) number of varieties pre and post-merger that arise for different values of the product differentiation parameter $\gamma$.

Let us write here the equilibrium upstream profits expressions after a merger upstream takes place for the three possible subgames:

$$
\Pi_{M}^{M 2}=\frac{a^{2}}{3+3 \gamma} ; \Pi_{M}^{M 3}=\frac{a^{2}}{2+4 \gamma} ; \Pi_{M}^{M 4}=\frac{2 a^{2}}{3+9 \gamma} .
$$

On the other hand, the equilibrium separated upstream firms' profits are given by:

$$
\begin{aligned}
& \Pi_{M_{1}}^{S 2}=\Pi_{M_{2}}^{S 2}=\frac{2 a^{2}(1-\gamma)}{3(1+\gamma)(2-\gamma)^{2}} . \\
& \Pi_{M_{1}}^{S 3}=\frac{a^{2}(1-\gamma)(2+3 \gamma)^{2}}{3(1+2 \gamma)(2+(2-\gamma) \gamma)^{2}} ; \Pi_{M_{2}}^{S 3}=\frac{2 a^{2}(1-\gamma)(1+\gamma)^{3}}{3(1+2 \gamma)(2+(2-\gamma) \gamma)^{2}} . \\
& \Pi_{M_{1}}^{S 4}=\Pi_{M_{2}}^{S 4}=\frac{a^{2}\left(1-\gamma^{2}\right)}{3+9 \gamma} .
\end{aligned}
$$

So let start with the case $\gamma<0.4046$. In this case, we can have equilibria $(2,2),(2,3)$, $(2,4),(3,4)$ and $(4,4){ }^{23}$ Let' s compare the upstream profits for all these cases. Let's start by equilibrium $(2,2)$, which occurs if $F \geq F_{1}^{S}(\gamma)$. We have to compute:

$$
\Pi_{M}^{M 2}-\left(\Pi_{M_{1}}^{S 2}+\Pi_{M_{2}}^{S 2}\right)=\frac{a^{2} \gamma^{2}}{3(1+\gamma)(2-\gamma)^{2}}>0 \text {, so the merger is profitable in this region. }
$$

Equilibrium $(2,3)$ occurs if $F_{2}^{S}(\gamma) \leq F<F_{1}^{S}(\gamma)$. We have to compute in this case:

$$
\Pi_{M}^{M 2}-\left(\Pi_{M_{1}}^{S 3}+\Pi_{M_{2}}^{S 3}-F\right)=\frac{a^{2}(-2+\gamma(-2+\gamma(7+4 \gamma(3+\gamma(2+\gamma)))))}{3(1+\gamma)(1+2 \gamma)\left(-2+\gamma(-2+\gamma)^{2}\right.}+F \geq 0 \text { as long as } F \geq \bar{F}_{23}(\gamma)=
$$
$-\frac{a^{2}(-2+\gamma(-2+\gamma(7+4 \gamma(3+\gamma(2+\gamma))))}{3(1+\gamma)(1+2 \gamma)\left(-2+\gamma(-2+\gamma)^{2}\right.}$. It is direct to check that $\bar{F}_{23}(\gamma)<F_{2}^{S}(\gamma)$ regardless of $\gamma$, which implies that the merger is profitable in this region.

Equilibrium $(2,4)$ occurs if $F_{1}^{M}(\gamma) \leq F<F_{2}^{S}(\gamma)$. We have to compute in this case:

$\Pi_{M}^{M 2}-\left(\Pi_{M_{1}}^{S 4}+\Pi_{M_{2}}^{S 4}-2 F\right)=\frac{a^{2}(1+\gamma(1+2 \gamma(1+\gamma)))}{3(1+\gamma)(1+3 \gamma)}+2 F \geq 0$ as long as $F \geq \bar{F}_{24}(\gamma)=$ $-\frac{a^{2}(-1+\gamma(1+2 \gamma(1+\gamma)))}{6(1+\gamma)(1+3 \gamma)}$. It is direct to check that $\bar{F}_{24}(\gamma)<F_{1}^{M}(\gamma)$ regardless of $\gamma$, which implies that the merger is profitable in this region.

Equilibrium $(3,4)$ occurs if $F_{2}^{M}(\gamma) \leq F<F_{1}^{M}(\gamma)$. We have to compute in this case:

$\Pi_{M}^{M 3}-\left(\Pi_{M_{1}}^{S 4}+\Pi_{M_{2}}^{S 4}-F\right)=\frac{a^{2}\left(-1+\gamma+4 \gamma^{2}+8 \gamma^{3}\right)}{6(1+\gamma(5+6 \gamma))}+F \geq 0$ as long as $F \geq \bar{F}_{34}(\gamma)=$ $-\frac{a^{2}\left(-1+\gamma+4 \gamma^{2}+8 \gamma^{3}\right)}{6(1+\gamma(5+6 \gamma))}$. It is direct to check that $\bar{F}_{34}(\gamma)<F_{2}^{M}(\gamma)$ regardless of $\gamma$, which implies that the merger is profitable in this region.

Equilibrium $(4,4)$ occurs if $F<F_{2}^{M}(\gamma)$. We have to compute in this case:

$\Pi_{M}^{M 4}-\left(\Pi_{M_{1}}^{S 4}+\Pi_{M_{2}}^{S 4}\right)=\frac{2 a^{2} \gamma^{2}}{3+9 \gamma}>0$, which implies that the merger is profitable in this region.

\footnotetext{
${ }^{23}$ The first number represents the number of varieties post-merger and the second one represents the number of varieties pre-merger.
} 
Let's go on with the case $0.4046<\gamma<0.6931$. In this case, we can have equilibria $(2$, $2),(2,3),(3,3),(3,4)$ and $(4,4)$. Let's compare the upstream profits for all the cases not analyzed previously (for equilibria $(2,2),(3,4)$ and $(4,4)$ the proof is already done above).

Equilibrium $(2,3)$ : it suffices to check that $\bar{F}_{23}(\gamma)<F_{2}^{M}(\gamma)$, which holds regardless of $\gamma$, so the merger is profitable in this region.

Equilibrium $(3,3)$ occurs if $F_{2}^{S}(\gamma) \leq F<F_{1}^{M}(\gamma)$. We have to compute in this case:

$\Pi_{M}^{M 3}-\left(\Pi_{M_{1}}^{S 3}+\Pi_{M_{2}}^{S 3}\right)=\frac{a^{2} \gamma^{2}(6+7 \gamma)}{6(1+2 \gamma)(-2+\gamma(-2+\gamma))^{2}}>0$, which implies that the merger is profitable in this region.

Let's go on with the case $0.6931<\gamma<0.7261$. In this case, we can have equilibria $(2$, $2),(2,3),(3,3),(4,3)$ and $(4,4)$. Let's compare the upstream profits for all the cases not analyzed previously (for equilibria $(2,2),(2,3),(3,3)$ and $(4,4)$ the proof is already done above).

Equilibrium $(4,3)$ occurs if $F_{2}^{S}(\gamma) \leq F<F_{2}^{M}(\gamma)$. We have to compute in this case: $\Pi_{M}^{M 4}-F-\left(\Pi_{M_{1}}^{S 3}+\Pi_{M_{2}}^{S 3}\right)=\frac{a^{2}(2+\gamma(1+\gamma(2+\gamma(-3+\gamma(17+10 \gamma))))}{3\left(-2+\gamma(-2+\gamma)^{2}(1+\gamma(5+6 \gamma))\right.}-F \geq 0$ as long as $F \leq \bar{F}_{43}(\gamma)=$ $\frac{a^{2}(2+\gamma(1+\gamma(2+\gamma(-3+\gamma(17+10 \gamma))))}{3\left(-2+\gamma(-2+\gamma)^{2}(1+\gamma(5+6 \gamma))\right.}$. It is direct to check that $\bar{F}_{43}(\gamma)>F_{2}^{M}(\gamma)$ regardless of $\gamma$, which implies that the merger is profitable in this region.

Let's go on with the case $0.7261<\gamma<0.8346$. In this case, we can have equilibria $(2$, $2),(3,2),(3,3),(4,3)$ and $(4,4)$. Let's compare the upstream profits for all the cases not analyzed previously (for equilibria $(2,2),(3,3),(4,3)$ and $(4,4)$ the proof is already done above).

Equilibrium $(3,2)$ occurs if $F_{1}^{S}(\gamma) \leq F<F_{1}^{M}(\gamma)$. We have to compute in this case:

$\Pi_{M}^{M 3}-F-\left(\Pi_{M_{1}}^{S 2}+\Pi_{M_{2}}^{S 2}\right)=\frac{a^{2}(4+\gamma(-8+\gamma(7+3 \gamma)))}{6(1+\gamma)(1+2 \gamma)(2-\gamma)^{2}}-F \geq 0$ as long as $F \leq \bar{F}_{32}(\gamma)=$ $\frac{a^{2}(4+\gamma(-8+\gamma(7+3 \gamma)))}{6(1+\gamma)(1+2 \gamma)(2-\gamma)^{2}}$. It is direct to check that $\bar{F}_{32}(\gamma)>F_{1}^{S}(\gamma)$ regardless of $\gamma$, which implies that the merger is profitable in this region.

Let's go on with the case $0.8346<\gamma<0.8425$. In this case, we can have equilibria $(2$, $2),(3,2),(3,3)$ and $(4,3)$. All the cases have been previously analyzed above.

Let's go on with the case $0.8425<\gamma<0.9164$. In this case, we can have equilibria $(2,2)$, $(3,2),(4,2)$ and $(4,3)$. Let's compare the upstream profits for all the cases not analyzed previously (for equilibria $(2,2),(3,2)$ and $(4,3)$ the proof is already done above).

Equilibrium $(4,2)$ occurs if $F_{1}^{S}(\gamma) \leq F<F_{2}^{M}(\gamma)$. We have to compute in this case:

$\Pi_{M}^{M 4}-2 F-\left(\Pi_{M_{1}}^{S 3}+\Pi_{M_{2}}^{S 3}\right)=\frac{2 a^{2}(2+\gamma(-1+\gamma)(4+\gamma))}{3(-2+\gamma)^{2}(1+\gamma)(1+3 \gamma)}-2 F \geq 0$ as long as $F \leq \bar{F}_{42}(\gamma)=$ $\frac{a^{2}(2+\gamma(-1+\gamma)(4+\gamma))}{3(-2+\gamma)^{2}(1+\gamma)(1+3 \gamma)}$.It is direct to check that $\bar{F}_{42}(\gamma)>F_{2}^{M}(\gamma)$ regardless of $\gamma$, which implies that the merger is profitable in this region. 
Equilibrium (4,3): it suffices to check that $\bar{F}_{43}(\gamma)>F_{1}^{S}(\gamma)$, which holds if $\gamma>0.3965$ (and this is satisfied as we are analyzing the range $0.8425<\gamma<0.9164$ ) so the merger is profitable in this region.

Let's go on finally with the case $\gamma>0.9164$.In this case, we can have equilibria $(2,2)$, $(3,2)$ and $(4,2)$. All of them have been already analyzed above, so the merger is profitable in this last region also.

\section{Concerning the merger effect on downstream profits:}

The equilibrium downstream profits under separated upstream firms for each possible subgame (2, 3 or 4 goods) are given by:

$$
\begin{aligned}
\Pi_{R_{1}}^{S 2} & =\Pi_{R_{2}}^{S 2}=\frac{2 a^{2}}{9(2-\gamma)^{2}(1+\gamma)} ; \\
\Pi_{R_{1}}^{S 3} & =\Pi_{R_{2}}^{S 3}=\frac{a^{2}(1+\gamma)(6+7 \gamma(2+\gamma))}{18(1+2 \gamma)(-2+\gamma(-2+\gamma))^{2}} ; \\
\Pi_{R_{1}}^{S 4} & =\Pi_{R_{2}}^{S 4}=\frac{a^{2}(1+\gamma)^{2}}{9+27 \gamma} .
\end{aligned}
$$

The equilibrium downstream profits under merged upstream firms for each possible subgame (2, 3 or 4 goods) are given by:

$$
\begin{aligned}
& \Pi_{R_{1}}^{M 2}=\Pi_{R_{2}}^{M 2}=\frac{a^{2}}{18+18 \gamma} ; \\
& \Pi_{R_{1}}^{M 3}=\Pi_{R_{2}}^{M 3}=\frac{a^{2}}{12+24 \gamma} ; \\
& \Pi_{R_{1}}^{M 4}=\Pi_{R_{2}}^{M 4}=\frac{a^{2}}{9+27 \gamma} .
\end{aligned}
$$

Now we have to compare the downstream profits in the merger and no merger cases for all the possible combinations of varieties that arise in equilibrium, that is: $(2,2),(3,3)$, $(4,4),(3,2),(4,2),(4,3),(2,3),(2,4),(3,4)$. The comparisons are straightforward for all the cases where after the merger we have equal or less variety, that is, for the cases $(2,2)$, $(3,3),(4,4),(2,3),(2,4),(3,4)$. For the rest of the cases we have:

Equilibrium $(3,2): \Pi_{R_{1}}^{M 3}-\Pi_{R_{1}}^{S 2}=\frac{a^{2}\left(3(2-\gamma)^{2}(1+\gamma)-8 a^{2}(1+2 \gamma)\right)}{36(2-\gamma)^{2}(1+\gamma)(1+2 \gamma)}<0$ only if $\gamma>0.2239$. But we know that equilibrium $(3,2)$ can arise only if $\gamma>0.7261$, so the merger reduces downstream firms' profits.

Equilibrium $(4,2): \Pi_{R_{1}}^{M 4}-\Pi_{R_{1}}^{S 2}<0$ only if $\gamma>0.2942$. But we know that equilibrium $(4,2)$ can arise only if $\gamma>0.8415$, so the merger reduces downstream firms' profits.

Equilibrium (4,3): $\Pi_{R_{1}}^{M 4}-\Pi_{R_{1}}^{S 3}<0$ only if $\gamma>0.1388$. But we know that equilibrium $(4,3)$ can arise only if $\gamma>0.6931$, so the merger reduces downstream firms' profits.

\section{Concerning the merger effect on consumer surplus:}

We will compare consumer surplus under both merged and separated upstream firms only for the cases where a merger increases variety (from 3 to 4 , from 2 to 4 or from 2 to 
3) because they are the only possible cases where consumer surplus could increase after a merger upstream.

Equilibrium $(4,3)$ : this equilibrium arises if $0.6931<\gamma<0.9164$. We have to sign:

$$
\begin{aligned}
& u\left(\frac{2 a}{6+18 \gamma}, \frac{2 a}{6+18 \gamma}, \frac{2 a}{6+18 \gamma}, \frac{2 a}{6+18 \gamma}\right)-\Pi_{M}^{M 4}-\Pi_{R_{1}}^{M 4}-\Pi_{R_{2}}^{M 4}- \\
& \left.-\left(u\left(\frac{a(2+3 \gamma)}{3(2+\gamma(6+(3-2 \gamma) \gamma))}, \frac{2 a(1+\gamma)^{2}}{6+3 \gamma(6+(3-2 \gamma) \gamma)}, \frac{a(2+3 \gamma)}{3(2+\gamma(6+(3-2 \gamma) \gamma))}, 0\right)-\Pi_{M_{1}}^{S 3}-\Pi_{M_{2}}^{S 3}-\Pi_{R_{1}}^{S 3}-\Pi_{R_{2}}^{S 3}\right)\right)= \\
& =\frac{a^{2}(2+\gamma(-6+\gamma(-49+\gamma(-78+\gamma(-35+4 \gamma))))}{9(1+\gamma(5+6 \gamma))(-2+\gamma(-2+\gamma))^{2}}<0 \text { if } \gamma>0.1388, \text { which implies that in the region }
\end{aligned}
$$

under consideration the merger upstream reduces consumer surplus.

Equilibrium $(4,2)$ : this equilibrium arises if $\gamma>0.8415$. We have to sign:

$$
\begin{aligned}
& u\left(\frac{2 a}{6+18 \gamma}, \frac{2 a}{6+18 \gamma}, \frac{2 a}{6+18 \gamma}, \frac{2 a}{6+18 \gamma}\right)-\Pi_{M}^{M 4}-\Pi_{R_{1}}^{M 4}-\Pi_{R_{2}}^{M 4}- \\
& \left.-\left(u\left(\frac{2 a}{6+3 \gamma-3 \gamma^{2}}, \frac{2 a}{6+3 \gamma-3 \gamma^{2}}, 0,0\right)-\Pi_{M_{1}}^{S 2}-\Pi_{M_{2}}^{S 2}-\Pi_{R_{1}}^{S 2}-\Pi_{R_{2}}^{S 2}\right)\right)= \\
& =\frac{2 a^{2}(2+\gamma(-6+\gamma(-3+\gamma))}{9(1+3 \gamma)(1+\gamma)(2-\gamma)^{2}}<0 \text { if } \gamma>0.2942, \text { which implies that in the region under consid- }
\end{aligned}
$$

eration the merger upstream reduces consumer surplus.

Equilibrium $(3,2)$ : this equilibrium arises if $\gamma>0.7261$. We have to sign:

$$
\begin{aligned}
& \quad u\left(\frac{2 a}{6+12 \gamma}, \frac{2 a}{6+12 \gamma}, \frac{2 a}{6+12 \gamma}, 0\right)-\Pi_{M}^{M 3}-\Pi_{R_{1}}^{M 3}-\Pi_{R_{2}}^{M 3}- \\
& \left.\quad-\left(u\left(\frac{2 a}{6+3 \gamma-3 \gamma^{2}}, \frac{2 a}{6+3 \gamma-3 \gamma^{2}}, 0,0\right)-\Pi_{M_{1}}^{S 2}-\Pi_{M_{2}}^{S 2}-\Pi_{R_{1}}^{S 2}-\Pi_{R_{2}}^{S 2}\right)\right)= \\
& =\frac{a^{2}(4+\gamma(-16+3 \gamma(-3+\gamma)))}{18(1+2 \gamma)(1+\gamma)(2-\gamma)^{2}}<0 \text { if } \gamma>0.2239 \text {, which implies that in the region under } \\
& \text { consideration the merger upstream reduces consumer surplus. }
\end{aligned}
$$

\section{Concerning the merger effect on social welfare:}

Social welfare: Given that we assume that there are no positive marginal production costs, it is direct to see that we can define the (gross of any product introduction costs) social welfare function simply as:

$$
W\left(Q_{1}, \ldots, Q_{N}\right)=u\left(Q_{1}, \ldots, Q_{N}\right)
$$

We have to compare social welfare under a merged upstream firm and under separated upstream firms for all possible combinations of varieties in equilibrium. We need first to compute the equilibrium quantities for each possible scenario by plugging the equilibrium wholesale prices (equations 2, 4 and 7) into the third stage equilibrium outputs. Doing so we get:

$$
\begin{aligned}
& q_{11}^{S 2}=q_{12}^{S 2}=q_{21}^{S 2}=q_{22}^{S 2}=\frac{a}{6+3 \gamma-3 \gamma^{2}} \\
& q_{11}^{S 3}=q_{12}^{S 3}=q_{31}^{S 3}=q_{32}^{S 3}=\frac{a(2+3 \gamma)}{6(2+\gamma(6+(3-2 \gamma) \gamma))} ; q_{21}^{S 3}=q_{22}^{S 3}=\frac{a(1+\gamma)^{2}}{6+3 \gamma(6+(3-2 \gamma) \gamma)} \\
& q_{11}^{S 4}=q_{12}^{S 4}=q_{21}^{S 4}=q_{21}^{S 4}=q_{31}^{S 4}=q_{32}^{S 4}=q_{41}^{S 4}=q_{42}^{S 4}=\frac{a(1+\gamma)}{6+18 \gamma} \\
& q_{11}^{M 2}=q_{12}^{M 2}=q_{21}^{M 2}=q_{22}^{M 2}=\frac{a}{6+6 \gamma},
\end{aligned}
$$




$$
\begin{aligned}
& q_{11}^{M 3}=q_{12}^{M 3}=q_{21}^{M 3}=q_{22}^{M 3}=q_{31}^{M 3}=q_{32}^{M 3}=\frac{a}{6+12 \gamma}, \\
& q_{11}^{M 4}=q_{12}^{M 4}=q_{21}^{M 4}=q_{22}^{M 4}=q_{31}^{M 4}=q_{32}^{M 4}=q_{41}^{M 4}=q_{42}^{M 4}=\frac{a}{6+18 \gamma} .
\end{aligned}
$$

By using these equilibrium outputs we can compare the net social welfare associated to each scenario:

We start in the region $\gamma<0.4046$. In this region we can have equilibria $(2,2),(2,3)$, $(2,4),(3,4),(4,4)$.

Equilibrium $(2,2)$ : we have to check the sign of:

$u\left(\frac{2 a}{6+6 \gamma}, \frac{2 a}{6+6 \gamma}, 0,0\right)-u\left(\frac{2 a}{6+3 \gamma-3 \gamma^{2}}, \frac{2 a}{6+3 \gamma-3 \gamma^{2}}, 0,0\right)=\frac{a^{2} \gamma(-8+5 \gamma)}{9\left(2-\gamma^{2}\right)(1+\gamma)}<0$, which implies that in this case the merger reduces social welfare.

Equilibrium $(2,3)$ : we have to sign:

$$
\begin{aligned}
& u\left(\frac{2 a}{6+6 \gamma}, \frac{2 a}{6+6 \gamma}, 0,0\right)-u\left(\frac{a(2+3 \gamma)}{3(2+\gamma(6+(3-2 \gamma) \gamma))}, \frac{2 a(1+\gamma)^{2}}{6+3 \gamma(6+(3-2 \gamma) \gamma)}, \frac{a(2+3 \gamma)}{3(2+\gamma(6+(3-2 \gamma) \gamma))}, 0\right)+F= \\
& =\frac{9 F(1+\gamma)(1+2 \gamma)(-2+\gamma(-2+\gamma))^{2}+a^{2}(-10+\gamma(-26+\gamma(-29+4 \gamma(-7+\gamma(-1+4 \gamma))))}{9(1+\gamma)(1+2 \gamma)(-2+\gamma(-2+\gamma))^{2}}<0 \text { if } \\
& F<F_{W 23}(\gamma)=\frac{a^{2}\left(10+\gamma\left(26+\gamma\left(29+4 \gamma\left(7+\gamma-4 \gamma^{2}\right)\right)\right)\right)}{9(1+\gamma)(1+2 \gamma)(-2+\gamma(-2+\gamma))^{2}} \text {. But we are in equilibrium }(2,3) \text { if } F_{2}^{S}(\gamma) \leq
\end{aligned}
$$
$F<F_{1}^{S}(\gamma)$. It is direct to check that $F_{W 23}(\gamma)>F_{1}^{S}(\gamma)$, which implies that in this case the merger reduces social welfare.

Equilibrium $(2,4)$ : we have to sign:

$$
\begin{aligned}
& u\left(\frac{2 a}{6+6 \gamma}, \frac{2 a}{6+6 \gamma}, 0,0\right)-u\left(\frac{2 a(1+\gamma)}{6+18 \gamma}, \frac{2 a(1+\gamma)}{6+18 \gamma}, \frac{2 a(1+\gamma)}{6+18 \gamma}, \frac{2 a(1+\gamma)}{6+18 \gamma}\right)+2 F= \\
& =\frac{18 F(1+\gamma)(1+3 \gamma)+a^{2}(-5+\gamma(-3+2 \gamma(-3+\gamma)))}{9(1+\gamma)(1+3 \gamma)}<0 \text { if } \\
& F<F_{W 24}(\gamma)=\frac{a^{2}(5+\gamma(3-2 \gamma(-3+\gamma)))}{18(1+\gamma)(1+3 \gamma)} \text {. But we are in equilibrium }(2,4) \text { if } F_{1}^{M}(\gamma) \leq F<
\end{aligned}
$$

$F_{2}^{S}(\gamma)$. It is direct to check that $F_{W 24}(\gamma)>F_{2}^{S}(\gamma)$, which implies that in this case the merger reduces social welfare.

Equilibrium $(3,4)$ : we have to sign:

$u\left(\frac{2 a}{6+12 \gamma}, \frac{2 a}{6+12 \gamma}, \frac{2 a}{6+12 \gamma}, 0\right)-u\left(\frac{2 a(1+\gamma)}{6+18 \gamma}, \frac{2 a(1+\gamma)}{6+18 \gamma}, \frac{2 a(1+\gamma)}{6+18 \gamma}, \frac{2 a(1+\gamma)}{6+18 \gamma}\right)+F=$

$=\frac{18 F(1+2 \gamma)(1+3 \gamma)+a^{2}(-5+\gamma(-11+4 \gamma(-7+2 \gamma)))}{18(1+\gamma)(5+6 \gamma)}<0$ if

$F<F_{W 34}(\gamma)=\frac{a^{2}(5+\gamma(11+4 \gamma(7-2 \gamma)))}{18(1+\gamma)(5+6 \gamma)}$. But we are in equilibrium $(3,4)$ if $F_{2}^{M}(\gamma) \leq F<$ $F_{1}^{M}(\gamma)$. It is direct to check that $F_{W 34}(\gamma)>F_{1}^{M}(\gamma)$, which implies that in this case the merger reduces social welfare.

Equilibrium $(4,4)$ : we have to sign:

$u\left(\frac{2 a}{6+18 \gamma}, \frac{2 a}{6+18 \gamma}, \frac{2 a}{6+18 \gamma}, \frac{2 a}{6+18 \gamma}\right)-u\left(\frac{2 a(1+\gamma)}{6+18 \gamma}, \frac{2 a(1+\gamma)}{6+18 \gamma}, \frac{2 a(1+\gamma)}{6+18 \gamma}, \frac{2 a(1+\gamma)}{6+18 \gamma}\right)=$ $=\frac{2 a^{2} \gamma(-4+\gamma)}{9+27 \gamma}<0$, which implies that in this case the merger reduces social welfare.

Let's move to the region $0.4046<\gamma<0.6931$.In this region we can have equilibria $(2,2)$, $(2,3),(3,3),(3,4),(4,4)$. We have already done $(2,2),(2,3)$ and $(4,4)$.

Equilibrium $(3,3)$ : we have to sign: 
$u\left(\frac{2 a}{6+12 \gamma}, \frac{2 a}{6+12 \gamma}, \frac{2 a}{6+12 \gamma}, 0\right)-u\left(\frac{a(2+3 \gamma)}{3(2+\gamma(6+(3-2 \gamma) \gamma))}, \frac{2 a(1+\gamma)^{2}}{6+3 \gamma(6+(3-2 \gamma) \gamma)}, \frac{a(2+3 \gamma)}{3(2+\gamma(6+(3-2 \gamma) \gamma))}, 0\right)=$

$=\frac{a^{2} \gamma(-32+\gamma(-66+\gamma(-10+27 \gamma)))}{18(1+2 \gamma)(-2+\gamma(-2+\gamma))^{2}}<0$, which implies that in this case the merger reduces social welfare.

Equilibrium $(3,4)$ : we are in equilibrium $(3,4)$ if $F_{2}^{M}(\gamma) \leq F<F_{2}^{S}(\gamma)$.It is direct to check that $F_{W 34}(\gamma)>F_{2}^{S}(\gamma)$, which implies that in this case the merger reduces social welfare.

Let's move to the region $0.6931<\gamma<0.7261$.In this region we can have equilibria $(2,2)$, $(2,3),(3,3),(4,3),(4,4)$. We have already done $(2,2),(2,3)$ and $(3,3)$ and $(4,4)$.

Equilibrium $(4,3)$ : we have to sign:

$u\left(\frac{2 a}{6+18 \gamma}, \frac{2 a}{6+18 \gamma}, \frac{2 a}{6+18 \gamma}, \frac{2 a}{6+18 \gamma}\right)-F-u\left(\frac{a(2+3 \gamma)}{3(2+\gamma(6+(3-2 \gamma) \gamma))}, \frac{2 a(1+\gamma)^{2}}{6+3 \gamma(6+(3-2 \gamma) \gamma)}, \frac{a(2+3 \gamma)}{3(2+\gamma(6+(3-2 \gamma) \gamma))}, 0\right)=$

$=\frac{-9 F(1+2 \gamma)(1+3 \gamma)(-2+\gamma(-2+\gamma))^{2}+a^{2}(10+\gamma(-6+\gamma(-101+\gamma(-114+\gamma(11+38 \gamma)))))}{9(1+\gamma)(5+6 \gamma)(-2+\gamma(-2+\gamma))^{2}}<0$ if $F>F_{W 43}(\gamma)=$ $\frac{a^{2}(10+\gamma(-6+\gamma(-101+\gamma(-114+\gamma(11+38 \gamma)))))}{9(1+\gamma(5+6 \gamma))(-2+\gamma(-2+\gamma))^{2}}$. But we are in equilibrium $(4,3)$ if $F_{2}^{S}(\gamma) \leq F<$ $F_{2}^{M}(\gamma)$. It is direct to check that $F_{W 43}(\gamma)<F_{2}^{S}(\gamma)$ if $\gamma>0.1464$, which holds in this region so this implies that in the region under consideration the merger reduces social welfare.

Let's move to the region $0.7261<\gamma<0.8346$.In this region we can have equilibria $(2,2)$, $(3,2),(3,3),(4,3)$ and $(4,4)$. We have already done $(2,2),(3,3),(4,3)$ and $(4,4)$.

Equilibrium $(3,2)$ : we have to sign:

$$
\begin{aligned}
& u\left(\frac{2 a}{6+12 \gamma}, \frac{2 a}{6+12 \gamma}, \frac{2 a}{6+12 \gamma}, 0\right)-F-u\left(\frac{2 a}{6+3 \gamma-3 \gamma^{2}}, \frac{2 a}{6+3 \gamma-3 \gamma^{2}}, 0,0\right)= \\
& =\frac{-18 F(2-\gamma)^{2}(1+2 \gamma)(1+\gamma)+a^{2}(20+\gamma(-56+3 \gamma(1+5 \gamma)))}{18(1+2 \gamma)(1+\gamma)(2-\gamma)^{2}}<0 \text { if } F>F_{W 32}(\gamma)=\frac{a^{2}(20+\gamma(-56+3 \gamma(1+5 \gamma)))}{18(1+2 \gamma)(1+\gamma)(2-\gamma)^{2}}
\end{aligned}
$$

But we are in equilibrium $(3,2)$ if $F_{1}^{S}(\gamma) \leq F<F_{1}^{M}(\gamma)$. It is direct to check that $F_{W 32}(\gamma)<$ $F_{1}^{S}(\gamma)$ if $\gamma>0.1954$, which holds in this region so this implies that in this case the merger reduces social welfare.

Let's move to the region $0.8346<\gamma<0.8415$.In this region we can have equilibria $(2,2)$, $(3,2),(3,3)$ and $(4,3)$. We have already done $(2,2),(3,2),(3,3)$.

Equilibrium (4,3): the merger reduces welfare if $F>F_{W 43}(\gamma)$. But we check that $F_{W 43}(\gamma)<0$ if $g>0.32$ so in the region under consideration $F>F_{W 43}(\gamma)$ and so the merger is anticompetitive.

Let's move to the region $0.8415<\gamma<0.9164$. In this region we can have equilibria $(2,2)$, $(3,2),(4,2)$ and $(4,3)$. We have already done $(2,2)$ and $(4,3)$.

Equilibrium $(3,2)$ : it is anticompetitive if $F>F_{W 32}(\gamma)=\frac{a^{2}(20+\gamma(-56+3 \gamma(1+5 \gamma)))}{18(1+2 \gamma)(1+\gamma)(2-\gamma)^{2}}$. But we are in equilibrium $(3,2)$ if $F_{2}^{M}(\gamma) \leq F<F_{1}^{M}(\gamma)$. It is direct to check that $F_{W 32}(\gamma)<F_{2}^{M}(\gamma)$ if $\gamma>0.2922$, which holds in this region, so in the region under consideration $F>F_{W 32}(\gamma)$ and so the merger is anticompetitive. 
Equilibrium $(4,2)$ : we have to sign:

$$
\begin{aligned}
& u\left(\frac{2 a}{6+18 \gamma}, \frac{2 a}{6+18 \gamma}, \frac{2 a}{6+18 \gamma}, \frac{2 a}{6+18 \gamma}\right)-2 F-u\left(\frac{2 a}{6+3 \gamma-3 \gamma^{2}}, \frac{2 a}{6+3 \gamma-3 \gamma^{2}}, 0,0\right)= \\
& =\frac{-18 F(2-\gamma)^{2}(1+3 \gamma)(1+\gamma)+2 a^{2}(10+\gamma(-24+\gamma(3+5 \gamma)))}{9(1+3 \gamma)(1+\gamma)(2-\gamma)^{2}}<0 \text { if } F>F_{W 42}(\gamma)=\frac{a^{2}(10+\gamma(-24+\gamma(3+5 \gamma)))}{9(1+3 \gamma)(1+\gamma)(2-\gamma)^{2}} .
\end{aligned}
$$

But we are in equilibrium $(4,2)$ if $F_{1}^{S}(\gamma) \leq F<F_{2}^{M}(\gamma)$. It is direct to check that $F_{W 42}(\gamma)<$ $F_{1}^{S}(\gamma)$ if $\gamma>0.2061$, which holds in this region so in the region under consideration $F>F_{W 42}(\gamma)$ and so the merger is anticompetitive.

Let's move to the region $\gamma>0.9164$. In this region we can have equilibria $(2,2),(3,2)$, $(4,2)$. We have already done $(2,2)$ and $(3,2)$.

Equilibrium $(4,2)$ : it is anticompetitive if $F>F_{W 42}(\gamma)=\frac{a^{2}(10+\gamma(-24+\gamma(3+5 \gamma)))}{9(1+3 \gamma)(1+\gamma)(2-\gamma)^{2}}$. We check that $F_{W 42}(\gamma)<0$ if $\gamma>0.4645$, which implies that in the region under consideration $F>F_{W 42}(\gamma)$ and so the merger is anticompetitive.

\section{Proof of Proposition 7}

In the case of separated firms, it is straightforward to find the equilibrium quantities and the respective profits:

$$
\begin{aligned}
& \widehat{q}_{i}^{S 2}=\frac{a}{2+\gamma} ; \widehat{q}_{1}^{S 3}=\widehat{q}_{3}^{S 3}=\frac{a(2-\gamma)}{2(2+(2-\gamma) \gamma)} ; \widehat{q}_{2}^{S 3}=\frac{a}{2+(2-\gamma) \gamma} ; \widehat{q}_{i}^{S 4}=\frac{a}{2+4 \gamma} \\
& \widehat{\Pi}_{M_{i}}^{S 2}=\frac{a^{2}}{(2+\gamma)^{2}} ; \widehat{\Pi}_{M_{1}}^{S 3}=\frac{a^{2}(2-\gamma)^{2}(1+\gamma)}{2(2+(2-\gamma) \gamma)^{2}} ; \widehat{\Pi}_{M_{2}}^{S 3}=\frac{a^{2}}{(2+(2-\gamma) \gamma)^{2}} ; \widehat{\Pi}_{M_{i}}^{S 4}=\frac{a^{2}(1+\gamma)}{2(1+2 \gamma)^{2}} .
\end{aligned}
$$

A necessary condition for "partial product introduction" to be an equilibrium is that $F \leq$ $\widehat{F}^{S}(\gamma)=\widehat{\Pi}_{M_{1}}^{S 3}=\frac{a^{2}(2-\gamma)^{2}(1+\gamma)}{2(2+(2-\gamma) \gamma)^{2}}$.

A necessary condition for "full product introduction" to be an equilibrium is that $F \leq$ $\widetilde{F}^{S}(\gamma)=\widehat{\Pi}_{M_{i}}^{S 4}=\frac{a^{2}(1+\gamma)}{2(1+2 \gamma)^{2}}$.

When is "no introduction" an equilibrium? The only possible deviation by, let's say, $M_{1}$ is to "partial product introduction". Now, if $F>\widehat{F}^{S}(\gamma)$, then such incentives do not exist. If $F \leq \widehat{F}^{S}(\gamma), M_{1}$ deviates only if $\widehat{\Pi}_{M_{1}}^{S 3}-F \geq \widehat{\Pi}_{M_{1}}^{S 2}$. This is satisfied as long as $F \leq \widehat{F}_{1}^{S}(\gamma)$, where $\widehat{F}_{1}^{S}(\gamma)=\frac{a^{2}(1-\gamma)\left(8+8 \gamma-\gamma^{4}\right)}{2\left(4+6 \gamma-\gamma^{3}\right)^{2}}$ and $\widehat{F}_{1}^{S}(\gamma)<\widehat{F}^{S}(\gamma)$.

When is "partial product introduction" an equilibrium? First of all, we know that it is not an equilibrium when $F>\widehat{F}^{S}(\gamma)$. When $F \leq \widehat{F}_{1}^{S}(\gamma)$, the possible deviation is for $M_{2}$ to produce 2 goods instead of 1 good. This deviation is profitable for $M_{2}$ as long as $\widehat{\Pi}_{M_{2}}^{S 4}-F \geq \widehat{\Pi}_{M_{2}}^{S 3}$, which holds if $F \leq \widehat{F}_{2}^{S}(\gamma)$, where $\widehat{F}_{2}^{S}(\gamma)=\frac{a^{2}}{2}\left(\frac{1+\gamma}{(1+2 \gamma)^{2}}-\frac{2}{(2+(2-\gamma) \gamma)^{2}}\right)$ and $\widehat{F}_{1}^{S}(\gamma)>\widehat{F}_{2}^{S}(\gamma)$.

When is "full introduction" an equilibrium? When $F \leq \widetilde{F}^{S}(\gamma)$, the only possible deviation is for M2 to produce 1 good instead of 2 goods. We know that this deviation is profitable for M2 as long as $F>F_{2}^{S}(\gamma)$. So, we conclude that "full introduction" is an 
equilibrium only when $F \leq \widehat{F}_{2}^{S}(\gamma)$.

Next, we turn to the case of a merger. It is straightforward to obtain the equilibrium quantities and profits:

$$
\begin{aligned}
& \widehat{q}_{i}^{M 2}=\frac{a}{2(1+\gamma)} ; \widehat{q}_{i}^{M 3}=\frac{a}{2(1+2 \gamma)} ; \widehat{q}_{i}^{M 4}=\frac{a}{2(1+3 \gamma)} . \\
& \widehat{\Pi}_{M}^{M 2}=\frac{a^{2}}{2+2 \gamma} ; \widehat{\Pi}_{M}^{M 3}=\frac{3 a^{2}}{4+8 \gamma} ; \widehat{\Pi}_{M}^{M 4}=\frac{a^{2}}{1+3 \gamma} .
\end{aligned}
$$

A necessary condition for "partial product introduction" to be an equilibrium is that $F \leq$ $\widehat{F}^{M}(\gamma)=\widehat{\Pi}_{M}^{M 3}$. A necessary condition for "full product introduction" to be an equilibrium is that $F \leq \widetilde{F}^{M}(\gamma)=\widehat{\Pi}_{M}^{M 4}$.

When is "no introduction" an equilibrium? It is always equilibrium when $F>\widetilde{F^{M}}(\gamma)$. When $\widehat{F}^{M}(\gamma)<F \leq \widetilde{F}^{M}(\gamma)$ the only possible deviation by the merged firm is to "full introduction". If instead $F \leq \widehat{F}^{M}(\gamma)$, there could be deviations to both "partial product introduction" and "full product introduction". If $F \leq \widehat{F}^{M}(\gamma), M$ deviates to three goods as long as $\widehat{\Pi}_{M}^{M 3}-F \geq \widehat{\Pi}_{M}^{M 2}$. This is satisfied if $F \leq \widehat{F}_{1}^{M}(\gamma)$, where $\widehat{F}_{1}^{M}(\gamma)=\frac{a^{2}(1-\gamma)}{4+12 \gamma+8 \gamma^{2}}$ and $\widehat{F}_{1}^{M}(\gamma)<\widehat{F}^{M}(\gamma)$. On the other hand, $M$ deviates to four goods only if $\widehat{\Pi}_{M}^{M 4}-2 F \geq \widehat{\Pi}_{M}^{M 2}$. This is satisfied as long as $F \leq \widehat{F}_{3}^{M}(\gamma)$, where $\widehat{F}_{3}^{M}(\gamma)=\frac{a^{2}(1-\gamma)}{2\left(2+8 \gamma+6 \gamma^{2}\right)}$ and $\widehat{F}_{1}^{M}(\gamma)>\widehat{F}_{3}^{M}(\gamma)$. In short, "no introduction" is an equilibrium if and only if $F>\widehat{F}_{1}^{M}(\gamma)$.

When is "partial product introduction" an equilibrium? First of all, we know that it is not an equilibrium when $F>\widehat{F}^{M}(\gamma)$. When $F \leq \widehat{F}^{M}(\gamma)$, the possible deviation is for $M$ to produce two goods or four goods instead of three goods. We know that a deviation to two goods is profitable for $\mathrm{M}$ as long as $F>\widehat{F}_{1}^{M}(\gamma)$. On the other hand, $M$ deviates to four goods only if $\widehat{\Pi}_{M}^{M 4}-F \geq \widehat{\Pi}_{M}^{M 3}$. This is satisfied as long as $F \leq \widehat{F}_{2}^{M}(\gamma)$, where $\widehat{F}_{2}^{M}(\gamma)=a^{2}\left(\frac{1}{3+\gamma}-\frac{3}{4+8 \gamma}\right)$ with $\widehat{F}_{1}^{M}(\gamma)>\widehat{F}_{3}^{M}(\gamma)>\widehat{F}_{2}^{M}(\gamma)$. So summarizing, "partial product introduction" is an equilibrium if and only if $\widehat{F}_{2}^{M}(\gamma)<F \leq \widehat{F}_{1}^{M}(\gamma)$.

When is "full introduction" an equilibrium? When $\widehat{F}^{M}(\gamma)<F \leq \widetilde{F}^{M}(\gamma)$, the only possible deviation is for $M$ to produce 2 goods instead of 4 goods, whereas if $F \leq \widehat{F}^{M}(\gamma)$, the possible deviations are for $M$ to produce 2 or 3 goods respectively. So, summarizing, "full introduction" is an equilibrium if and only if $F \leq \widehat{F}_{2}^{M}(\gamma)$ (recall that the ranking between the different relevant threshold values of $F$ is $\widehat{F}_{2}^{M}(\gamma)<\widehat{F}_{3}^{M}(\gamma)<\widehat{F}_{1}^{M}(\gamma)<\widehat{F}^{M}(\gamma)<\widetilde{F}^{M}(\gamma)$ and so $F \leq \widehat{F}_{2}^{M}(\gamma)$ also implies $\left.F \leq \widehat{F}_{3}^{M}(\gamma)\right)$.

(i) Comparing the critical values between the merger and the no merger case we find that $\widehat{F}_{2}^{M}(\gamma)<\widehat{F}_{1}^{M}(\gamma)<\widehat{F}_{2}^{S}(\gamma)<\widehat{F}_{1}^{S}(\gamma)$. Therefore, the merger leads to less product variety when $\widehat{F}_{2}^{M}<F<\widehat{F}_{1}^{S}$. In all other cases, product variety is the same with merger 
and with no merger.

(ii) Comparing the equilibrium profits under a merger with the respective ones under no merger in all the possible areas that arise from the second stage equilibrium, we find that the profits of the merged manufactures are higher than the sum of the profits of the two separated manufacturers.

(iii) Following similar steps as in the proof of Proposition 6(ii), we conclude that both the consumers' surplus and the total welfare are lower in the merger case than in the no merger case.

\section{Proof of Proposition 8}

We have to compare the equilibrium number of varieties in a one-tier market with the ones in a two-tier market for both the scenario where the manufacturers remain separated and the scenario where they merge. Starting with the former scenario, it is direct to see that $F_{2}^{S}(\gamma)<F_{1}^{S}(\gamma)<\widehat{F}_{2}^{S}(\gamma)<\widehat{F}_{1}^{S}(\gamma)$, which implies that (i) for $F<F_{2}^{S}(\gamma)$, we have the same number of varieties (4) in both markets, (ii) for $F_{2}^{S}(\gamma)<F<F_{1}^{S}(\gamma)$ we have more product introduction in the one-tier (4 goods) compared with the two-tier market (only 3 goods), (iii) for $F_{1}^{S}(\gamma)<F<\widehat{F}_{2}^{S}(\gamma)$ we have more product introduction in the one-tier (4 goods) compared with the two-tier market (only 2 goods), (iv) for $\widehat{F}_{2}^{S}(\gamma)<F<\widehat{F}_{1}^{S}(\gamma)$ we have we have more product introduction in the one-tier (3 goods) compared with the two-tier market (only 2 goods) and, finally, (v) for $F>\widehat{F}_{2}^{S}(\gamma)$ we have the same number of varieties in both scenarios (2 goods).

Next, we have to do the same analysis for the case in which the two manufacturers merge. Compare now threshold values in the one-tier market with the corresponding ones for the case of a two-tier market, it is direct to see that when $\gamma<0.33$ we have that $F_{2}^{M}(\gamma)<F_{1}^{M}(\gamma)<\widehat{F}_{2}^{M}(\gamma)<\widehat{F}_{1}^{M}(\gamma)$ which, following the same line of argument that we follow above for the case of no merger, implies that product introduction is always larger or equal in a one-tier market than in a two-tier market. When instead $\gamma>0.33$, we have that $F_{2}^{M}(\gamma)<\widehat{F}_{2}^{M}(\gamma)<F_{1}^{M}(\gamma)<\widehat{F}_{1}^{M}(\gamma)$, which implies that (i) for $F<F_{2}^{M}(\gamma)$, we have the same number of varieties (4) in both scenarios, (ii) for $F_{2}^{M}(\gamma)<F<\widehat{F}_{2}^{M}(\gamma)$ we have more product introduction in the one-tier (4 goods) compared with the two-tier market (only 3 goods), (iii) for $\widehat{F}_{2}^{M}(\gamma)<F<F_{1}^{M}(\gamma)$ we have the same number of goods in both scenarios (3), (iv) for $F_{1}^{M}(\gamma)<F<\widehat{F}_{1}^{M}(\gamma)$ we have we have more product introduction in the one-tier (3 goods) compared with the two-tier market (only 2 goods) and, finally, (v) 
for $F>\widehat{F}_{1}^{M}(\gamma)$ we have the same number of varieties in both scenarios (2 goods).

\section{References}

Alexander, P.M., 1997. Product Variety and Market Structure: A New Measure and a Simple Test. Journal of Economic Behavior and Organization 32, 207-214.

Avenel, E. and Caprice, S., 2006. Upstream Market Power and Product Line Differentiation in Retailing. International Journal of Industrial Organization 24, 319-334.

Bernheim, B.D. and Whinston, M.D., 1998. Exclusive Dealing. Journal of Political Economy 106, 64-103.

Berry, S. and Waldfogel, J., 2001. Do Mergers Increase Product Variety? Evidence from Radio Broadcasting. Quarterly Journal of Economics 116, 1009-1025.

Brander, J.A. and Eaton, J., 1984. Product Line Rivalry. American Economic Review $74,323-334$.

Chang, M.H., 1992. Exclusive Dealing Contracts in a Successive Duopoly with Side Payments. Southern Economic Journal 59, 180-193.

Chen, Y. and Schwartz, M., 2013. Product Innovation Incentives: Monopoly versus Competition. Journal of Economics and Management Science 22, 513-528.

Davidson, C. and Deneckere, R., 1985. Incentives to Form Coalitions with Bertrand Competition. Rand Journal of Economics 16, 473-486.

De Fraja, G., 1993. Relaxing Spatial Competition through Product Line Choice (or vice versa). Regional Science and Urban Economics, 23, 461-486.

Dhillon, A. and Petrakis, E., 2002. A Generalized Wage Rigidity Result. International Journal of Industrial Organization 20, 285-311.

Dobson, P.W. and Waterson, M., 1996. Exclusive Trading Contracts in Successive Differentiated Duopoly. Southern Economic Journal 63, 361-377.

Dobson, P. and Waterson, M., 1997. Countervailing Power and Consumer Prices. Economic Journal 107, 418-430.

Eaton, B. and Lipsey, R., 1979. The Theory of Market Pre-emption: The Persistence of Excess Capacity and Monopoly in Growing Spatial Markets' Economica, 46, 149-58.

Fan, Y., 2013. Ownership Consolidation and Product Characteristics: A Study of the US Daily Newspaper Market. American Economic Review 103, 1598-1628. 
Farrell, J. and Shapiro, C., 1988. Horizontal Mergers: An Equilibrium Analysis. American Economic Review 80, 107-126.

Fauli-Oller, R., 2008. Capacity Restrictions by Retailers. Mimeo. Universidad de Alicante.

Fauli-Oller, R. and Bru, L., 2008. Horizontal Mergers for Buyer Power. Economics Bulletin 12, 1-7.

Faulí-Oller, R., Sandonís, J. and J. Santamaría, 2011. Downstream Mergers and Upstream Investment. The Manchester School 79, 884-898.

Faulí-Oller, R. and Sandonís, J., 2014. Welfare Effects of Downstream Mergers and Upstream Market Concentration. The Singapore Economic Review, forthcoming.

Froeb, L., Tschantz, S. and Werden, G., 2007. Vertical Restraints and the Effects of Upstream Horizontal Mergers, in The Political Economy of Antitrust, V. Ghosal, V., and Stennek, S. (Eds.), Amsterdam: North-Holland Publishing.

Gandhi, A., Froeb, L., Tschantz, S. and Werden, G., 2008. Post-merger Product Repositioning. Journal of Industrial Economics 56, 49-67.

George, L., 2007. What's Fit to Print: The Effect of Ownership Concentration on Product Variety in Daily Newspaper Markets. Information Economics and Policy 19, 285303.

Gilbert, R. and Matutes, C., 1993. Product Line Rivalry and Brand Differentiation. Journal of Industrial Economics 41, 223-240.

Gotz, G. and Gugler, K., 2006. Market Concentration and Product Variety under Spatial Competition: Evidence from Retail Gasoline. Journal of Industry, Competition and Trade 6, 225-234.

Greenstain S. and Ramey G., 1998. Market Structure, Innovation and Vertical Product Differentiation. International Journal of Industrial Organization 16, 285-311.

Horn, H. and Wolinsky, A., 1988. Bilateral Monopolies and Incentives for Mergers. Rand Journal of Economics 19, 408-419.

Inderst, R., 2010, Models of Vertical Market Relations, International Journal of Industrial Organization 28, 341-344.

Inderst, R. and Shaffer, G., 2007. Retail Merger, Buyer Power and Product Variety. Economic Journal 117, 45-67.

Inderst, R. and Wey, C., 2003. Bargaining, Mergers and Technology Choice in Bilaterally Oligopolistic Industries, Rand Journal of Economics 34, 1-19. 
Inderst, R. and Wey, C., 2011. Countervailing Power and Dynamic Efficiency. Journal of the European Economic Association 9, 702-720.

Lancaster, K., 1990. The Economics of Product Variety: a Survey. Marketing Science 9, 189-206.

Lommerud, K. and Sørgard, L., 1997. Merger and Product Range Rivalry. International Journal of Industrial Organization 16, 21-42.

Lommerud, K., O. Straume and Sørgard, L., 2005. Downstream Merger with Upstream Market Power. European Economic Review 49, 717-743.

Martínez-Giralt, X. and Neven, D., 1988. Can Price Competition Dominate Market Segmentation? Journal of Industrial Economics 36, 431-443.

Mauleon, A., J.J. Sempere-Monerris, and Vannetelbosch, V., 2011, Networks of Manufacturers and Retailers. Journal of Economic Behavior and Organization 77, 351-367.

Mazzeo, M., Seim, K. and Varela, M., 2012. The Welfare Consequences of Mergers with Product Repositioning. Mimeo, Kellogg School of Management.

Miklós-Thal, J., Rey, P. and Vergé, T., 2010. Vertical Relations. International Journal of Industrial Organization 28, 345-349.

Milliou, C. and Petrakis, E., 2007, Upstream Horizontal Mergers, Vertical Contracts, and Bargaining. International Journal of Industrial Organization 25, 963-987.

Milliou, C., Petrakis, E. and Sloev, I., 2013. Equilibrium Product Variety and Market Structure in Successive Oligopolies. Mimeo, Athens University of Economics and Business.

Milliou, C. and Pavlou, A., 2013. Upstream Mergers, Downstream Competition and R\&D Investments. Journal of Economics and Management Strategy 22, 787-809.

Moner-Colonques, R., J.J. Sempere-Monerris, and Urbano, A., 2004, The Manufacturers' Choice of Distribution Policy under Successive Duopoly. Southern Economic Journal $70,532-548$.

Moner-Colonques, R., Sempere-Monerris, J.J. and Urbano, A., 2011. Product Line Choice in Retail Duopoly. Journal of Economics and Management Strategy 20, 777-802.

O'Brien, D. and Shaffer, G., 1993. On the Dampening-of-Competition Effects of Exclusive Dealing. Journal of Industrial Economics 41, 215-221.

O'Brien, D. and Shaffer, G., 1997. Nonlinear Supply Contracts, Exclusive Dealing and Equilibrium Market Foreclosure. Journal of Economics and Management Strategy 6, 755785.

O'Brien, D. and Shaffer, G., 2003. Bargaining, Bundling and Clout: The Portfolio 
Effects of Horizontal Mergers. Rand Journal of Economics 36, 573-595.

Perry, M. and Porter, R., 1985. Oligopoly and the Incentives for Horizontal Merger. American Economic Review 75, 219-227.

Raubitschek, R.S., 1987. A Model of Product Proliferation with Multiproduct Firms. Journal of Industrial Economics 3, 269-279.

Reynolds, R., Salant, S. and Switzer, S,. 1983. Losses from Horizontal Merger: The Effects of an Exogenous Change in Industry Structure on Cournot-Nash Equilibrium. Quartely Journal of Economics 98, 185-199.

Salop, S., 1979. Monopolistic Competition with Outside Goods. Bell Journal of Economics 10, 141-156.

Schmalensee, R., 1978. Entry Deterrence in the Ready-to-Eat Breakfast Cereal Industry. Bell Journal of Economics IX, 305-327.

Singh, V. and Vives, X., 1985. On the Efficiency of Bertrand and Cournot Equilibria with Product Differentiation. Journal of Economic Theory 34, 166-175.

Symeonidis, G., 2008. Downstream Competition, Bargaining and Welfare. Journal of Economics and Management Strategy 17, 247-270.

Symeonidis, G., 2010. Downstream Merger and Welfare in a Bilateral Oligopoly. International Journal of Industrial Organization 28, 230-243.

Von Ungern-Sternberg, T.,1996. Countervailing Power Revisited. International Journal of Industrial Organization 14, 507-520.

Watson, R., 2009. Product Variety and Competition in the Retail Market for Eyeglasses. Journal of Industrial Economics 57, 217-251.

U.S. Department of Justice and FTC, 2010, Horizontal Merger Guidelines, Washington, DC.

Ziss, S., 1995. Vertical Separation and Horizontal Mergers. Journal of Industrial Economics $43,63-75$. 